\title{
ADOLESCENT BINGE DRINKING INCREASES EXPRESSION OF THE DANGER SIGNAL RECEPTOR AGONIST HMGB1 AND TOLL-LIKE RECEPTORS IN THE ADULT PREFRONTAL CORTEX
}

\author{
R. P. Vetreno* and F. T. Crews \\ The Bowles Center for Alcohol Studies, Department of Psychiatry, The University of North \\ Carolina at Chapel Hill, Chapel Hill, NC 27599, USA
}

\begin{abstract}
Adolescence is a critical developmental stage of life during which the prefrontal cortex (PFC) matures, and binge drinking and alcohol abuse are common. Recent studies have found that ethanol increases neuroinflammation via upregulated high-mobility group box 1 (HMGB1) signaling through Toll-like receptors (TLRs). HMGB1/TLR 'danger signaling' induces multiple brain innate immune genes that could alter brain function. To determine whether adolescent binge drinking persistently increases innate immune gene expression in the PFC, rats (P25-P55) were exposed to adolescent intermittent ethanol (AIE [5.0 g/kg, 2-day on/2-day off schedule]). On P56, HMGB1/TLR danger signaling was assessed using immunohistochemistry (i.e., + immunoreactivity $[+\mathrm{IR}])$. In a separate group of subjects, spatial and reversal learning on the Barnes maze was assessed in early adulthood (P64-P75), and HMGB1/TLR danger signaling was measured using immunohistochemistry for +IR and RT-PCR for mRNA in adulthood (P80). Immunohistochemical assessment at P56 and 24 days later at P80 revealed increased frontal cortical HMGB1, TLR4, and TLR3 in the AIE-treated rats. Adolescent intermittent ethanol treatment did not alter adult spatial learning on the Barnes maze, but did cause reversal learning deficits and increased perseverative behavior. Barnes maze deficits correlated with the expression of danger signal receptors in the PFC. Taken together, these findings provide evidence that adolescent binge drinking leads to persistent upregulation of innate immune danger signaling in the adult PFC that correlates with adult neurocognitive dysfunction.
\end{abstract}

\section{Keywords}

ethanol; reversal learning; neuroimmune; innate immunity; Barnes maze

\section{INTRODUCTION}

Chronic alcohol exposure in adulthood activates microglia and astrocytes (Qin and Crews, 2012), and increases the expression of cytokines, chemokines, oxidases, and other innate immune genes in mouse brain (Qin et al., 2008; Crews et al., 2011; Qin and Crews, 2012). These findings in animal models mimic changes in postmortem human alcoholic brain (He and Crews, 2008; Qin and Crews, 2012). In humans, initiation of alcohol use typically

\footnotetext{
(C) 2012 IBRO. Published by Elsevier Ltd. All rights reserved.

"Corresponding author. Address: The Bowles Center for Alcohol Studies, The University of North Carolina at Chapel Hill, Department of Psychiatry, CB \#7178, 1021 Thurston-Bowles Building, Chapel Hill, NC 27599, USA., rvetreno@email.unc.edu (R. P. Vetreno).
}

CONFLICT OF INTEREST

The authors report no conflicts of interest. 
occurs during adolescence. Alcohol consumption during adolescence is highly prevalent as $8 \%$ of 8 th grade, $16 \%$ of 10 th grade, and $25 \%$ of 12 th grade adolescent individuals reported heavy episodic drinking (i.e., $<5$ consecutive alcohol drinks per episode) over the past 2 weeks (Johnston et al., 2009). This heavy drinking pattern persists into college as $44 \%$ of students report binge drinking every 2 weeks and 19\% report $>3$ binge drinking episodes per week (Wechsler et al., 1995; O'Malley et al., 1998). Heavy drinking among adolescent males was found to increase impulsivity the following year in those individuals predisposed to adolescent-typical impulsivity (White et al., 2011). Furthermore, early onset of alcohol use ( $<13$ years of age) was associated with increased drinking frequency and physical violence (Gruber et al., 1996), which is consistent with diminished impulse inhibition. In addition, adolescents and adults with alcohol use disorders evidence deficits in executive functioning (Brown et al., 2000; Tapert and Brown, 2000; Hanson et al., 2011). The frontal cortex continues to develop throughout adolescence and is uniquely sensitive to ethanol neurotoxicity (Crews et al., 2000) and studies in adults find neuroimmune activation contributes to ethanol neurotoxicity. These findings prompted investigation into the impact of models of underage binge drinking on adult prefrontal cortex (PFC) expression of HMGB1/TLR danger signaling molecules, neuroimmune activation, and cognition.

Activation of the innate immune system persists for long periods of time in the adult brain (Qin et al., 2007, 2008). However, the long-term effect of neuroimmune activation in the adolescent brain has not been studied. The high incidence of underage drinking increases the importance of understanding whether there are long-term persistent changes in the brain. We hypothesized that adolescent intermittent ethanol (AIE) exposure would persistently alter adult prefrontal cortical structure and function by elevating neuroinflammatory HMGB 1/ TLR danger signal expression. Twenty-four hours after AIE treatment concluded, HMGB1/ TLR + IR was assessed using immunohistochemistry. In early adulthood (P80), we assessed + IR using immunohistochemistry and mRNA expression of danger signal receptors (i.e., TLR4, TLR3, TLR2) as well as the danger signaling agonist HMGB1 25 days after the conclusion of ethanol treatment. Furthermore, we assessed spatial and reversal learning on the Barnes maze to evaluate cognition. We found that AIE treatment upregulated the expression of TLR4, TLR3, and HMGB1 in the adolescent PFC that persisted into adulthood, and impaired reversal learning while increasing perseveration. Persistent upregulation of frontal cortical danger signaling molecules correlated with reversal learning deficits. Together, these findings support the hypothesis that early onset of alcohol exposure persistently activates innate immune danger signaling in the brain, which might contribute to adult neurocognitive dysfunction.

\section{EXPERIMENTAL PROCEDURES}

\section{Animals}

Time-mated young pregnant female Wistar rats (embryonic day 17), ordered from Harlan Sprague-Dawley (Indianapolis, IN), were allowed to acclimate to the animal facilities prior to birthing. On postnatal day (P)1 (24 h after birth), litters were culled to 10 pups per dam. Litters were housed on a 12/12 h light-dark cycle (light onset at $700 \mathrm{~h}$ ) in a temperature (20 ${ }^{\circ} \mathrm{C}$ ) and humidity-controlled vivarium, and provided ad libitum access to food and water. All experimental procedures were approved and conducted according to the Institutional Animal Care and Use Committee of the University of North Carolina at Chapel Hill.

\section{Adolescent intermittent ethanol treatment paradigm}

On P21, male subjects were weaned and randomly assigned to one of the following treatment conditions: (i) adolescent intermittent ethanol (AIE, $n=16$ ) or (ii) water-treated control (CON, $n=16$ ). Beginning on P25, animals in the AIE condition received intragastric 
(i.g.) administration of ethanol $(5.0 \mathrm{~g} / \mathrm{kg}, 20 \%$ ethanol w/v) on a 2-day on/2-day off schedule until P55. Animals in the CON condition received comparable volumes of $\mathrm{H}_{2} \mathrm{O}$ on a 2-day on/2-day off schedule for the same duration. As seen in Fig. 1, the body weights of AIEtreated animals did not differ significantly from the CON animals $(p>0.35)$. Tail blood was collected to assess blood ethanol content (BEC) one hr after ethanol administration on P38 and P54 as depicted in Fig. 1. Tail BECs were calculated using a GM7 Analyzer (Analox; London, UK). Mean BEC levels ( \pm SEM) on P38 were $134 \pm 8 \mathrm{mg} / \mathrm{dL}$ and at P54 were $165 \pm$ $17 \mathrm{mg} / \mathrm{dL}$. These BEC levels following i.g. ethanol treatment are consistent with previous studies using i.g. ethanol treatment of adolescent mice (Crews et al., 2006b).

\section{Barnes maze spatial and reversal learning assessment}

The Barnes maze was used to assess spatial learning and memory as well as the rats' ability to reverse a previously learned response. The Barnes maze $(121 \mathrm{~cm}$ in diameter) was constructed of gray PVC and situated $100 \mathrm{~cm}$ from the floor. It contained 20 holes $(10 \mathrm{~cm}$ in diameter) that were evenly spaced along the perimeter of the maze (see Cheng et al., 2006). A hidden box was situated directly beneath one of the holes to serve as an escape. The testing room had numerous visual cues, and the maze was brightly illuminated with spotlights to provide incentive for the rat to enter the hidden escape box. An automated tracking system (Ethovision XT 8.0, Noldus Ethovision; Leesburg, VA) was used to measure the distance traveled $(\mathrm{cm})$, latency to enter goal box $(\mathrm{s})$, velocity $(\mathrm{cm} / \mathrm{s})$, error duration (s), and frequency. The criterion for acquisition of learning was a 15-s average latency of all the rats in each treatment group to enter the hidden escape box. Between each trial, the maze and escape box was thoroughly cleansed (Roccal-D Plus, Fisher Scientific; Pittsburgh, PA) to remove all olfactory cues.

Spatial learning-Spatial learning commenced on P64 with each subject semi-randomly assigned a specific escape hole (1-20) beneath which the box was situated. The assigned escape hole was maintained for each animal for the duration of spatial learning. Before the start of each trial, the animal was placed in an opaque start cylinder that prevented the subject from determining its spatial location. The cylinder containing the rat was then placed on the Barnes maze in one of four possible randomly ordered start locations. Following a 10-s interval, the cylinder was lifted and the animal was allotted $5 \mathrm{~min}$ to locate and enter the escape box. Rats were given one trial per day for 6 days until the criterion of acquisition of learning was achieved.

Reversal learning — The animals were assessed for their ability to "unlearn" the previous location of the escape box and to learn a new location of the escape box. Reversal learning training began on P70, and the escape hole used during the spatial learning component was rotated $180^{\circ}$. The rat was released from the start cylinder identically to the spatial learning component. Rats were given one trial per day for 6 days until the criterion of learning was achieved. In addition to the measures collected, time and entries into the spatial goal quadrant were collected as a measure of perseveration. Perseveration was defined as repetitive entry and/or increased time spent in the previous spatial goal quadrant during reversal learning.

Probe trial-Five days after the completion of reversal learning, the rat was returned to the Barnes maze on P79 for a 2-min trial in which the escape box was not available. Duration and number of entries into the newly learned quadrant was collected.

\section{Perfusion, brain tissue preparation, and immunohistochemistry}

On P56 and P80, rats were anesthetized with sodium pentobarbital (100 mg/kg, i.p.) and transcardially perfused with $0.1 \mathrm{M}$ phosphate-buffered saline (PBS, $\mathrm{pH} 7.4$ ) followed by 
4.0\% paraformaldehyde in PBS. Brains were extracted and post-fixed in $4.0 \%$ paraformaldehyde/PBS solution for $24 \mathrm{~h}$ followed by 4 days of fixation in a $30 \%$ sucrose solution. Brain tissue was sectioned coronally $(40 \mu \mathrm{m})$ on a sliding microtome (MICROM HM450; ThermoScientific, Austin, TX). Sections were sequentially collected into well plates, and stored at $-20^{\circ} \mathrm{C}$ in a cryoprotectant solution consisting of $30 \%$ glycol and $30 \%$ ethylene glycol for immunohistochemistry (IHC). Free-floating sections were washed in 0.1 M PBS, incubated in $0.3 \% \mathrm{H}_{2} \mathrm{O}_{2}$, and blocked with normal serum (goat or rabbit; MP Biomedicals, Solon, $\mathrm{OH}$ ). Sections were incubated in primary antibody (Abcam, Cambridge, MA: rabbit anti-TLR4 [1:200], rabbit anti-HMGB1 [1:500]; Santa Cruz Biotechnology, Santa Cruz, CA: goat anti-TLR3 [1:100], goat anti-TLR2 [1:100]) for $24 \mathrm{~h}$ at $4{ }^{\circ} \mathrm{C}$. Sections were then washed with PBS, incubated for $1 \mathrm{~h}$ in biotinylated secondary antibody (1:200; Vector Laboratories, Burlingame, CA), and incubated for $1 \mathrm{~h}$ in avidin- biotin complex solution (Vectastain ABC Kit, Vector Laboratories). The chromogen, nickel-enhanced diaminobenzidine (Sigma-Aldrich, St. Louis, MO), was used to visualize immunoreactivity. Tissue was mounted onto slides, dehydrated, and coverslipped. Negative control for nonspecific binding was conducted on separate sections employing the abovementioned procedures with the exception that the primary antibody was omitted.

\section{Double immunofluorescence and confocal analysis}

Free-floating sections from P80 subjects were washed in $0.1 \mathrm{TBS}$, incubated in $0.3 \% \mathrm{H}_{2} \mathrm{O}_{2}$, and blocked with normal horse serum (MP Biomedicals). Sections were incubated for $48 \mathrm{~h}$ at $4{ }^{\circ} \mathrm{C}$ in primary antibody cocktail with neuronal-specific nuclear protein (mouse antiNeuN [1:500]; Millipore, Temecula, CA), and either rabbit anti-TLR4 (1:100), rabbit antiHMGB1 (1:500), or goat anti-TLR3 (1:100). Sections were then washed in TBS, incubated for $2 \mathrm{~h}$ at room temperature in the appropriate secondary antibody cocktail (Alexa Fluor 594 [anti-mouse] and Alexa Fluor 488 [anti-goat or anti-rabbit]; Invitrogen, Carlsbad, CA). Confocal analysis was performed using an inverted Zeiss 510 Meta laser scanning confocal microscope (Carl Zeiss MicroImaging, Thomwood, NY) in the Michael Hooker microscopy facility at UNC equipped with standard high-power objectives and corresponding software (LSM 510 META). Single optical Z-stacks ( $1 \mu \mathrm{m}$; 1 -airy unit) were collected, and the number of TLR/HMGB 1 cells that co-localized with NeuN were counted (approximately 100 TLR/HMGB1 + IR cells per subject).

\section{Microscopic quantification and image analysis}

Assessment of TLR4, TLR2, and HMGB1 immunoreactivity (+IR) was performed in the prelimbic cortex (PrL [Bregma: $+4.70 \mathrm{~mm}$ to $+2.20 \mathrm{~mm}$ ) and infralimbic cortex (IL [Bregma: $+3.20 \mathrm{~mm}$ to $+2.20 \mathrm{~mm}$ ]) according to the atlas of Paxinos and Watson (2004). Since expression of TLR3 + IR cells was limited to the outer layers of the frontal cortex, assessment was confined to the frontal cortex area 2 (FC2 [Bregma: $+4.70 \mathrm{~mm}$ to +2.20 $\mathrm{mm}]$ ) according to the atlas of Paxinos and Watson (2004). For all animal IHC protocols, sections were assessed in a 1:6 series containing the region of interest (see Fig. 2). Across studies, Bioquant Nova Advanced Image Analysis (R\&M Biometric, Nashville, TN) was used for image capture and analysis. Images were captured using an Olympus BX50 microscope and Sony DXC-390 video camera linked to a computer. A modified stereological profile count method was used to quantify cells within regions of interest for TLR4 + IR, TLR3 + IR, TLR2 + IR, and HMGB1 + IR cells (Crews et al., 2004), and data are expressed as cells per $\mathrm{mm}^{2}$. For each measure, the microscope, camera, and software were background correct and normalized to preset light levels to ensure fidelity of data acquisition. 


\section{Real-time PCR analysis}

Total RNA was extracted from frontal cortical brain samples of adult rats exposed to either AIE or CON treatment conditions. Frontal cortical tissue samples were collected anterior to the union of the corpus callosum (approximately $+1.60 \mathrm{~mm}$ according to the atlas of Paxinos and Watson (2004)), and reverse transcribed as previously described (see Zou et al., 2012). The primers used are presented in Table 1. The SYBR green PCR master mix (Applied Biosystems, Foster City, CA) was used for real-time PCR analysis. The relative differences in expression between groups were expressed as cycle time $(\mathrm{Ct})$ values normalized with $\beta$ actin, and relative differences between CON- and AIE-treated animals were calculated and expressed as the percentage difference relative to CONs.

\section{Statistical analyses}

Statistics were performed using SPSS (Chicago, IL). Analysis of variance (ANOVA) was employed to determine the effects of AIE on BEC, IHC, and RT-PCR mRNA expression. Repeated measure ANOVAs were used to assess the effects of AIE on body weight and Barnes maze spatial and reversal learning measures. Pearson correlations $(r)$ were used to determine the significance between the IHC and behavior (i.e., Barnes maze). All values are reported as mean $\pm \mathrm{SEM}$, and significance was defined at a level of $p \leq 0.05$.

\section{RESULTS}

\section{Adolescent intermittent ethanol exposure increases the expression of danger signal receptors and the agonist HMGB1 in the adolescent prefrontal cortex, which persists into adulthood}

Adolescent rats showed dramatic growth throughout the 30-day treatment period (P25-P55) that was not significantly altered by AIE treatment, as AIE- and CON-treated animals evidenced identical mean body weights at P80 (see Fig. 1).

To determine whether adolescent binge ethanol exposure persistently upregulated proinflammatory gene expression, we conducted immunohistochemical analysis (+IR) in three subregions of the adolescent (P56) and adult (P80) PFC (see Fig. 2). In addition, we dissected the frontal cortex of adult (P80) male rats and measured mRNA levels to verify our finding of persistently upregulated danger signaling in the adult following adolescent binge ethanol exposure. Assessment of TLR4 + IR cells in CON adolescent PFC revealed sparse expression characterized by distinct hollow neuron-like silhouettes. TLR4 + IR cells in the PFC of AIE-treated adolescents were more numerous and darkly stained (see Fig. 3C). Control adult TLR4 + IR cells were more sparsely distributed throughout the tissue than the adolescent CONs and appeared as +IR cells lacking distinct cytoplasmic and nuclear borders. TLR4 + IR cells in the PFC of AIE-treated adults appeared as darkly stained cell bodies with distinct borders (see Fig. 3D). In CON animals, we found a significant ageassociated 52\% reduction in TLR4 + IR cells in the PrL from adolescence to adulthood $(F=$ $44.4, p<0.01$ ). Similarly, we found a $66 \%$ maturational reduction of TLR $4+$ IR cells in the IL from adolescence to adulthood $(F=103.9, p<0.01)$. We next assessed AIE-induced changes in TLR4 + IR and found significant age-associated reductions of TLR4 + IR cells across subjects from P56 to P80 in both the PrL (main effect of Age: $F=96.8, p<0.01$ ) and IL (main effect of Age: $F=70.7, p<0.01$ ), regardless of treatment. TLR4 + IR cells in the PrL of AIE-treated animals were increased by $141 \pm 4 \%(F=61.5, p<0.01)$ in the adolescent and $210 \pm 7 \%(F=45.1, p<0.01)$ in the adult (see Fig. 3A). Adolescent binge ethanol exposure also significantly increased TLR $4+$ IR cells in the adolescent IL by $116 \%$ $\pm 6 \%(F=6.2, p<0.05)$ and $254 \pm 21 \%(F=30.9, p<0.01)$ in the adult (see Fig. 3B). Measures of TLR4 mRNA in the adult frontal cortex revealed a threefold increase in the AIE-treated animals relative to CON subjects ( $F=65.9, p<0.01$; see Fig. 6). Thus, levels of 
TLR4 + IR in the PFC show a developmental decline while adolescent binge ethanol exposure increases TLR4 expression in the adolescent PFC that persists into adulthood.

Across treatment and ages, TLR3 + IR cells were primarily localized in cortical layers $2 / 3$ of the PFC (see Fig. 4C). TLR3 + IR cells in both groups and ages appear as hollow neuronlike silhouettes with process staining (see Fig. 4B). Similar to TLR4 in the CON subjects, we found a significant 53\% maturational reduction of TLR3 + IR cells in CON FC2 from adolescence to adulthood $(F=29.1, p<0.01)$. When we assessed AIE-induced changes, we found that TLR3 + IR cells declined significantly with age (main effect of Age: $F=32.3, p$ $<0.01$ ), regardless of treatment. Twenty-four hours after the completion of adolescent binge ethanol treatment, AIE subjects had a significant $145 \pm 10 \%$ increase in TLR3 + IR cells in the FC2 $(F=11.6, p<0.01)$. Twenty-five days later, adult AIE-treated rats had a $223 \pm 19 \%$ increase ( $F=32.3, p<0.01$; see Fig. 4A). Assessment of TLR3 mRNA in the adult PFC of AIE-treated subjects revealed a twofold increase relative to CONs $(F=8.9, p<0.05$; see Fig. 6). These data reveal that binge ethanol exposure during adolescence not only interferes with the maturational reduction of TLR3 in the PFC, but also persistently upregulates the expression of TLR3 in the adult.

A third danger signal receptor, TLR2, was assessed in the adult PFC. The CON frontal cortex samples revealed measurable TLR2 mRNA levels, and TLR2 expression was sparsely distributed throughout the tissue. Assessment of TLR2 mRNA in the frontal cortex samples from AIE-treated animals did not reveal any differences relative to CONs. Similarly, quantification of immunohistochemistry did not reveal AIE-induced alterations in the protein expression of TLR2 (data not shown). Taken together, these data indicate that TLR2, TLR3 and TLR4 receptors are expressed in the adult PFC, and binge ethanol exposure during adolescence leads to persistent increases in adult PFC TLR4 and TLR3 expression.

High-mobility group box 1 (HMGB1) is a common danger signaling cytokine known to bind to TLR2, TLR3, and TLR4 (Sims et al., 2010). In addition to its role as a proinflammatory cytokine, it is also critically involved in the regulation of DNA bending and transcription stability (Paull et al., 1993; Thomas, 2001) as well as neurogenesis and cell migration (Fages et al., 2000; Zhao et al., 2011). In CON animals, we found a significant age-associated $191 \%$ increase in HMGB1 + IR cells in the PrL of adult rats compared to adolescents $(F=42.1, p$ $<0.01)$. Similarly, we found a $195 \%$ maturational increase of HMGB1 + IR cells in the IL of adults relative to adolescents $(F=91.8, p<0.01)$. In order to identify a potential mechanism for TLR upregulation in the AIE PFC, we assessed adolescent and adult expression of HMGB 1 following AIE treatment in the PFC. HMGB1 + IR cells were homogeneously expressed throughout the adolescent and adult prefrontal cortical tissue, regardless of treatment, and appeared as solid nuclei and hollow somas (see Fig. 5C, D). Age-associated increases in HMGB1 + IR were observed in the PrL (main effect of Age: $F=$ $105, p<0.01)$. Adolescent binge ethanol exposure significantly increased HMGB1 + IR in the adolescent $\operatorname{PrL}(174 \pm 5 \%[F=79.5, p<0.01])$, which persisted into adulthood (160 \pm $8 \%[F=37.1, p<0.01]$ see Fig. 5A). Similarly, HMGB1 + IR cell populations were increased in both the adolescent $(157 \pm 9 \%[F=26.6, p<0.01])$ and adult IL $(143 \pm 4 \%$ $[F=56.6, p<0.01]$ ) following AIE treatment (see Fig. 5B). Assessment of HMGB1 mRNA in the frontal cortex samples from AIE-treated animals revealed a significant $180 \%$ increase relative to CON subjects $(F=9.2, p<0.05$; see Fig. 6$)$. Taken together, these data indicate that AIE treatment leads to persistently increased levels of HMGB1 in both the PrL and IL of the adolescent and adult PFC as well as increased expression of danger signal receptors TLR3 and TLR4. 
To determine the cellular location of danger signals in the adult PFC, double immunofluorescence was performed to assess colocalization of NeuN (a neuronal marker) with TLR4, TLR3, and HMGB1. Employing confocal microscopy, we found that $88 \pm 1 \%$ and $89 \pm 2 \%$ of TLR $4+$ IR cells colocalized with neurons $(p>0.8)$ in the CON- and AIEtreated prefrontal cortex, respectively. TLR3 colocalization was observed in $89 \pm 4 \%$ of neurons in CON subjects and $89 \pm 2 \%$ of neurons in the AIE-treated subjects $(p>0.9)$. In CON subjects, $79 \pm 2 \%$ HMGB 1 colocalized in NeuN + IR cells whereas $84 \pm 3 \%$ of HMGB1 + IR cells in the AIE PFC colocalized with NeuN ( $p>0.2$; see Fig. 7). Adolescent binge ethanol exposure did not affect neuronal distribution of danger signals. However, we did find that a significant proportion of HMGB1/TLR danger signaling occurs through neurons.

\section{Reversal learning, but not spatial learning, is impaired in adult rats exposed to adolescent intermittent ethanol treatment}

Previous studies have found that adolescent ethanol treatment of mice does not affect Morris water maze spatial learning, but does disrupt reversal learning, which involves the PFC (Coleman et al., 2011). We used the Barnes maze to assess spatial and reversal learning in this study using Wistar rats. Following AIE treatment, subjects were assessed on P64 using a 20-hole modified version of the Barnes maze (see Cheng et al., 2006) as shown in Fig. 1. Spatial learning was assessed from P64 to P69, and both treatment groups learned to locate and enter the escape box to criterion levels by P69 (CON: $12 \pm 2$ s; AIE: $10 \pm 2$ s). Although there was no effect of AIE on latency to enter the escape box during the spatial learning component (both $p$ 's $>0.2$ ), subjects did reduce their escape latency across trials (main effect of Trial: $F=15.3, p<0.01$ ), demonstrating that subjects in both groups were actively learning the spatial component (see Fig. 8A). There was no effect of AIE treatment on error time (time spent in wrong quadrant) or error frequency (number of entries into wrong quadrant) during spatial learning (all $p$ 's $>0.5$ ), but both measures improved significantly in both groups as trials progressed (main effect of Trial: both $F \mathrm{~s}>15.2, p<0.01$ ). Adolescent intermittent ethanol treatment did not affect distance traveled $(\mathrm{cm})$ or velocity $(\mathrm{cm} / \mathrm{s})$ during spatial learning (all $p$ s $>0.5$ ), but animals, regardless of treatment, reduced their distance traveled and increased their velocity across trials (main effects of Trial: both $F \mathrm{~s}>5.3, p<$ 0.01 ). Assessment of boli counts during the spatial learning component revealed that AIEtreated animals defecated more than CONs (main effect of Treatment: $F=5.6, p<0.05$ ), which has been suggested to indicate increased anxiety-like behavior (Bruhwyler et al., 1990). Thus, AIE treatment did not alter spatial learning on the Barnes maze.

Reversal learning refers to the ability to alter a previously learned behavioral response with a new response when outcomes do not match those predicted by the preceding cues (Stalnaker et al., 2009). In animal models, reversal learning tasks are used to assess frontal cortical function. Previous work from our laboratory found that binge ethanol exposure in adolescent mice tested as adults (Coleman et al., 2011) and rats both treated and tested as adults (Obernier et al., 2002) impaired reversal learning on the Morris water maze. Following attainment of criterion on the spatial learning component, reversal learning was assessed in animals $24 \mathrm{~h}$ later beginning on P70. Adolescent intermittent ethanol exposure significantly increased the latency to locate and enter the reversal goal box (2-way repeated measures ANOVA: $F=4.1, p<0.05)$. On the first trial of reversal learning, AIE-treated animals $(73 \pm 9 \mathrm{~s})$ required $60 \%$ more time than the CON animals $(44 \pm 8 \mathrm{~s})$ to locate and enter the reversal goal box $(F=6.0, p<0.05$; see Fig. 8B). Similarly, AIE-treated animals on the first trial of reversal learning traveled greater distances than CONs (2-way repeated measures ANOVA: $F=3.4, p<0.05$ ) although AIE treatment did not affect velocity (2-way ANOVA: both $p$ 's $>0.2$ ). All animals increased their velocity across trials (main effect of Trial: $F>6.5, p<0.01$ ). Assessment of maze defecation revealed that boli counts were 
greater in the AIE-treated animals than the CONs (main effect of Treatment: $F=6.0, p<$ $0.05)$. These data indicate that AIE treatment-induced reversal learning deficits in adult adulthood are consistent with prolonged changes in PFC following AIE.

Frontal cortical dysfunction results in perseveration (i.e., repetition of a previously learned behavior), and might have contributed to the observed reversal learning impairments on the Barnes maze. For quantification, perseveration was defined as increased time spent in the previous spatial goal quadrant during reversal learning. Intermittent ethanol exposure during adolescence significantly increased perseveration (2-way repeated measures ANOVA: $F=$ 4.6, $p<0.01)$. Adolescent intermittent ethanol exposure increased time spent in the spatial previous goal quadrant $(39 \pm 6 \mathrm{~s})$ than the CONs $(21 \pm 6 \mathrm{~s})$ during the first trial of reversal learning (one-way ANOVA: $F=4.8, p<0.05$; see Fig. $8 \mathrm{C}$, D). There were no behavioral differences between AIE- and CON-treated rats during probe trial assessment (data not shown). Together, these data reveal that reversal learning deficits observed in the AIEtreated adults are likely the consequence of increased perseveration, a symptom of PFC dysfunction.

\section{Danger signal receptor expression in the adult prefrontal cortex is correlated with reversal learning and perseveration-like behaviors on the Barnes maze}

We used correlations to investigate potential relationships between behavior during the first trial of reversal learning, and increased expression of HMGB1, TLR3, and TLR4 danger signal molecules in the PFC. Interestingly, TLR4 + IR cells in the PrL robustly correlated with measures of reversal learning (see Table 2, Fig. 9), but not IL. Controls contribute to the correlation as those animals demonstrating the lowest PrL TLR4 + IR showing the shortest latency to enter the new reversal goal, which is consistent with PFC-mediated behavioral plasticity (see Fig. 9). Interestingly, TLR3 + IR in the FC2 was also robustly correlated with both reversal learning and perseverative behaviors. Both TLR4 + IR and TLR3 + IR significantly correlated with reversal learning deficits, but in different prefrontal cortical brain regions. Prefrontal cortical HMGB1 + IR was not significantly correlated with behavior on the Barnes maze (data not shown). Taken together, these data suggest PFC TLR4 and TLR3 expression are associated with AIE-induced PFC reversal learning deficits.

\section{Induction of danger signaling agonist HMGB1 correlates with TLR induction}

HMGB1/TLR danger signaling contributes to positive loops of neuroimmune activation that are thought to mediate the persistence of neuroimmune responses (Crews et al., 2011). We sought to determine whether there was a relationship between expression of danger signal molecules and expression of the danger signaling cytokine HMGB1 in PFC. HMGB1 expression in PFC correlated with expression of TLR4 and TLR3 in PFC (see Table 3). HMGB1 expression was significantly correlated with TLR4 and TLR3 expression regardless of brain region. A comparison of HMGB1 and TLR4 + IR in the PrL reveals clear clusters of CONs with low levels of both receptors, and AIE-treated animals with about double levels of both danger signaling molecules (see Fig. 10). These correlations are consistent with HMGB1/TLR signaling being induced in parallel as components of the amplification and the persistence of neuroimmune activation in the brain.

\section{DISCUSSION}

In the present study, we tested the hypothesis that adolescent binge ethanol exposure would (1) elevate neuroimmune danger signaling molecules in the adolescent PFC that would persist into adulthood, and (2) alter adult behavior indicative of prefrontal cortical dysfunction. We found that AIE exposure $(5.0 \mathrm{~g} / \mathrm{kg}$, i.g., 2-day on/2-day off 30-day schedule) significantly increased adolescent (+IR) and adult (+IR) expression of the danger 
signal receptors TLR4 and TLR3 in the PFC. The persistent increase of danger signal receptors was accompanied by an upregulation of the danger signaling cytokine, HMGB1, in the adolescent and adult PFC. Interestingly, we also found development-associated reductions of TLR4 and TLR3, and increased expression of HMGB1 in the PFC. Confocal assessment of HMGB1, TLR4, and TLR3 expression revealed a high incidence (80-90\%) of colocalization with NeuN + IR neurons in the adult PFC. Adult rats exposed to AIE were behaviorally impaired on the reversal learning component of the Barnes maze, which provides a measure of the rats' ability to modify a previously learning behavioral response when outcomes do not match those predicted by the preceding cue, i.e. behavioral plasticity (Stalnaker et al., 2009). We found that expression of danger signal receptors TLR4 and TLR3 correlated with error and perseverative behavior on the Barnes maze. Interestingly, we did not observe a correlation between HMGB1 expression in the PFC and behavioral dysfunction, suggesting that other factors might be involved. Although we do not yet have a clear understanding of all of the mechanisms underlying innate immune danger signalinginduced behavioral dysfunction, we have found that adolescent binge ethanol exposure results in persistent danger signaling upregulation and long-term behavioral inflexibility in adulthood.

We have previously found that chronic ethanol treatment of adult rodents increases neuroimmune activation through the induction of brain NF- $\mathrm{kB}$-proinflammatory target genes, including COX (Knapp and Crews, 1999), NOX (Qin and Crews, 2012), and multiple cytokines, proteases, and oxidases (Qin et al., 2008; Zou and Crews, 2010; Qin and Crews, 2012) as well as increasing NF-kB-DNA binding in vivo (Crews et al., 2006a) and in in vitro brain slice culture (Zou and Crews, 2006). The exact mechanisms of ethanol-induced neuroimmune activation are not clear, but appear to involve TLR4 receptors. In a series of experiments, Guerri and colleagues have shown that transgenic mice lacking TLR4 have a blunted ethanol neuroimmune response in microglia (Fernandez-Lizarbe et al., 2009), astrocytes (Blanco et al., 2005), and in mouse brain in vivo (Alfonso-Loeches et al., 2010). TLR4 receptors are critically involved in the activation of monocytes and microglia (Fernandez-Lizarbe et al., 2009; Yang et al., 2010), which is consistent with microglia initiating neuroimmune responses following ethanol exposure (Block and Hong, 2005; Crews et al., 2011). Although HMGB1 can bind to and activate multiple TLRs, its signaling mechanism is complex due to neuroimmune amplification within and across cells that release additional HMGB 1, other cytokines, and proinflammatory molecules that contribute to the response (Sims et al., 2010; Vezzani et al., 2011). HMGB1 is a ubiquitously expressed nuclear protein, but when released, it exerts cytokine-like actions on multiple TLRs promoting neuroimmune activation through NF- $\mathrm{\kappa B}$ transcription of proinflammatory genes that spreads via autocrine and paracrine processes (see Fig. 11 [Park et al., 2004; Rauvala and Rouhiainen, 2010; Volz et al., 2010]). This activation leads to the induction of NF- $\mathrm{KB}$ and activator protein-1 that is accompanied by an upregulation of inducible NOS and $\mathrm{COX}-2$ expression in astrocytes that leads to further downstream activation of the NF- $\mathrm{\kappa B}$ signaling pathway (Blanco et al., 2005). Activation of the NF- $\mathrm{kB}$ signaling pathway stimulates the release of $\mathrm{TNFa}$, which stimulates further NF- $\mathrm{kB}$ transcription through the activation of TNFR1, and is amplified in an autocrine and paracrine fashion. These positive loops of neuroimmune activation lead to persistently increased oxidative free radicals from oxidases, increased TLR expression and the formation of endogenous TLR agonists, and chemokine and cytokine receptor upregulation (Qin et al., 2008; Zou and Crews, 2010).

In the present study, we found increased HMGB1, TLR4, and TLR3 expression in the adolescent prefrontal cortex $24 \mathrm{~h}$ after the conclusion of binge ethanol exposure. In rat brain slice culture, we also found that ethanol caused the release of HMGB1 and induced IL1 $\beta$ through TLR4 signaling suggesting that one mechanism of ethanol-induced brain neuroimmune activation may involve HMGB1-TLR4 signaling (Crews et al., in press). Our 
finding of persistently increased HMGB1/TLR expression in the adult PFC following AIE treatment supports the hypothesis that ethanol activates positive loops of neuroimmune activation, which contribute to the observed persistence of HMGB1/TLR upregulation. Indeed, several studies have found that activation of the neuroimmune system in the CNS leads to persistent neuroimmune gene activation in the brain. We previously found that a single dose of lipopolysaccharide (LPS; $5 \mathrm{mg} / \mathrm{kg}$ ), the prototypical TLR4 agonist, persistently increased TNFa protein and mRNA expression in the mouse brain that persisted for at least 10 months (Qin et al., 2007) in the absence of a further neuroimmune challenge. Similarly, binge ethanol exposure $(5 \mathrm{~g} / \mathrm{kg}$, i.g. for 10 days $)$ persistently upregulated levels of brain MCP-1 for at least 7 days after the conclusion of ethanol treatment (Qin et al., 2008). Interestingly, in this study we found a high incidence of HMGB1/TLR expression in neurons. Although the mechanisms of ethanol-induced neuroimmune activation are complex, our findings of persistent increases in neuronal HMGB1, TLR4, and TLR3 are consistent with HMGB1-TLR signaling initiating and maintaining brain neuroimmune activation. The results of the present study complement and extend the finding that once the innate immune danger signaling system is stimulated, it remains activated for a significant amount of time, and perhaps for the life of the organism.

In addition to their involvement in pathological neurodegeneration (Okun et al., 2009), HMGB1/TLR signaling also has a physiological role in the regulation of neural development, neurogenesis, and neurite outgrowth (Trudler et al., 2010; Fang et al., 2012). In the CON subjects, we found maturational reductions of TLR4 and TLR3 in the PFC from adolescence (P56) to adulthood (P80). This age-associated reduction of TLR4 and TLR3 in the PFC parallels the observed neurotransmitter receptor gene declination between adolescence and adulthood (Coleman et al., 2011). We also found that HMGB1 + IR cell populations increased from adolescence (P56) to adulthood (P80). Although the data concerning HMGB1 are limited, it appears to be involved in neurite outgrowth (Fages et al., 2000) as well as neurogenesis as it is associated with survival and proliferation of neural progenitors during brain development in the zebra fish (Zhao et al., 2011). These observations reveal the need to more fully explore the physiological role that the innate immune system plays in brain development and plasticity.

Assessment of Barnes maze performance revealed that AIE treatment did not impair spatial learning and memory, or motor function. However, AIE treatment did lead to reversal learning impairments in the adult rats. Although this effect might be due to AIE-induced facilitation of reference memory in adult rats exposed to adolescent binge drinking, this interpretation is unlikely given the similar rate of spatial learning between groups. A second explanation for the impaired reversal learning is that AIE treatment increased perseverative behavior, which is characterized by repetitive re-entry into the quadrant that contained the spatial goal. Indeed, the AIE-treated animals spent significantly more time in the spatial goal quadrant during the first trial of reversal learning. The observed inability of AIE-treated animals to modify their previously learned behavior in response to a change in outcomes suggests a deficit in the ability to set-shift (i.e., the capacity for behavioral flexibility). Lesion studies report that the medial PFC (mPFC), defined as the PrL and IL, contribute to perseverative behaviors (Kosaki and Watanabe, 2012). However, reversal learning impairments are also associated with damage to the orbitofrontal cortex (OFC), a region of the PFC that is also involved in reversal learning (see Schoenbaum and Shaham, 2008). Although clear behavioral delineations between the OFC and mPFC (i.e., PrL and IL) are lacking, Badanich and colleagues (2011) suggest that the OFC is critical for reversal learning while the $\mathrm{mPFC}$ is involved in set-shifting. The impaired reversal learning is indicative of prefrontal cortical dysfunction, which has been found in human alcoholics (Fortier et al., 2008) and individuals with neurodegenerative disorders (Oscar-Berman and Zola-Morgan, 1980; Freedman and Oscar-Berman, 1989). Regardless, we found that 
adolescent binge ethanol exposure resulted in adult reversal learning deficits and increased perseverative behavior following a long period of abstinence, which paralleled the persistent nature of long-term innate immune gene induction.

In addition to the involvement of danger signal receptors in neuroinflammation, these receptors also modulate cognitive and emotive functioning (Dantzer et al., 2008; Okun et al., 2010; Hanke and Kielian, 2011; Yirmiya and Goshen, 2011). Our findings of increased TLR4, TLR3, and HMGB1 in the adult PFC suggest that alcohol-induced danger signaling during adolescence may alter developmental maturation through neuroinflammation-induced hyperexcitability. Increased transcription of HMGB1 and elevated TLR4 expression results in glutamatergic hyperexcitability as well as a lowering of hippocampal seizure threshold (see Vezzani et al., 2011 for a review). We found that expression of danger signal receptors was predictive of error and perseverative behaviors on the Barnes maze. Although our data demonstrate correlations across measures of innate immune activation and behavior, these data do not definitively prove that the danger responses are solely responsible. Indeed, it is plausible that a loss of cholinergic cells, a consistently observed finding (Ehlers et al., 2011), might also contribute to the observed behavioral impairments. However, it is noteworthy to mention that a clear role for the CNS cholinergic system in modulating neuroinflammation has been found (Nizri et al., 2008, 2009). Consistent with our findings, activation of innate immune danger signaling in animal models of systemic inflammation are associated with reversal learning disruption (MacFabe et al., 2011; Jurgens et al., 2012). Furthermore, transient activation of innate immune danger signaling during early life was found to facilitate hyperexcitability in adulthood, as exposure to LPS at P14-reduced seizure threshold in adult rats treated with pilocarpine (Riazi et al., 2010). We observed correlations between ethanol-induced innate immune activation and persistent changes to behavior that are consistent with previous studies. Pascual and colleagues (2007) studied adolescent binge ethanol exposure in rats (3 g/kg, i.p. 2-day on/2-day off from P25-38) and found increased COX-2 and inducible NOS levels $24 \mathrm{~h}$ after the conclusion of treatment. Further, they found that adolescent binge ethanol exposure impaired discrimination learning and object recognition 20 days later, which was recovered in animals treated with indomethacin, a COX-2 inhibitor. These data support our finding that binge ethanol exposure during adolescence causes persistent neuroimmune activation that appears to contribute to behavioral dysfunction.

\section{CONCLUSION}

Adolescent binge ethanol exposure led to persistent upregulation of the danger signaling agonist HMGB1, and the danger signal receptors, TLR4 and TLR3, in the adolescent PFC that persists into adulthood. Further, AIE treatment imparted long-term reversal learning impairment, which is indicative of a dysfunctional PFC. The persistent increase in danger signaling is correlated with the adult prefrontal neurocognitive dysfunction. Together, these data are consistent with underage binge drinking exerting long lasting neuroimmune changes in the developing CNS that impact adult neurocognitive function, which might facilitate later development of neuroinflammatory disease.

\section{Acknowledgments}

This work was supported in part by the National Institutes of Health, National Institute on Alcoholism and Alcohol Abuse [AA020023, AA020024, AA020022, AA019767, AA11605, AA007573, and AA021040] and the Bowles Center for Alcohol Studies. The authors thank Diana Lotito for help with the preparation of the manuscript. 


\section{Abbreviations}

$\begin{array}{ll}\text { AIE } & \text { adolescent intermittent ethanol } \\ \text { BEC } & \text { blood ethanol content } \\ \text { FC2 } & \text { frontal cortex area } 2 \\ \text { HMGB1 } & \text { high-mobility group box 1 } \\ \text { IHC } & \text { immunohistochemistry } \\ \text { IL } & \text { infralimbic cortex } \\ \text { +IR } & \text { immunoreactivity } \\ \text { LPS } & \text { lipopolysaccharide } \\ \text { OFC } & \text { orbitofrontal cortex } \\ \text { PFC } & \text { prefrontal cortex } \\ \text { PrL } & \text { prelimbic cortex } \\ \text { TLR } & \text { Toll-like receptor }\end{array}$

\section{REFERENCES}

Alfonso-Loeches S, Pascual-Lucas M, Blanco AM, Sanchez-Vera I, Guerri C. Pivotal role of TLR4 receptors in alcohol-induced neuroinflammation and brain damage. J Neurosci. 2010; 30:82858295. [PubMed: 20554880]

Badanich KA, Becker HC, Woodward JJ. Effects of chronic intermittent ethanol exposure on orbitofrontal and medial prefrontal cortex-dependent behaviors in mice. Behav Neurosci. 2011; 125:879-891. [PubMed: 22122149]

Blanco AM, Valles SL, Pascual M, Guerri C. Involvement of TLR4/type I IL-1 receptor signaling in the induction of inflammatory mediators and cell death induced by ethanol in cultured astrocytes. $\mathrm{J}$ Immunol. 2005; 175:6893-6899. [PubMed: 16272348]

Block ML, Hong JS. Microglia and inflammation-mediated neurodegeneration: multiple triggers with a common mechanism. Prog Neurobiol. 2005; 76:77-98. [PubMed: 16081203]

Brown SA, Tapert SF, Granholm E, Delis DC. Neurocognitive functioning of adolescents: effects of protracted alcohol use. Alcohol Clin Exp Res. 2000; 24:164-171. [PubMed: 10698367]

Bruhwyler J, Chleide E, Liegeois JF, Delarge J, Mercier M. Anxiolytic potential of sulpiride, clozapine and derivatives in the open-field test. Pharmacol Biochem Behav. 1990; 36:57-61. [PubMed: 2349269]

Cheng G, Whitehead SN, Hachinski V, Cechetto DF. Effects of pyrrolidine dithiocarbamate on betaamyloid (25-35)-induced inflammatory responses and memory deficits in the rat. Neurobiol Dis. 2006; 23:140-151. [PubMed: 16624564]

Coleman LG Jr, He J, Lee J, Styner M, Crews FT. Adolescent binge drinking alters adult brain neurotransmitter gene expression, behavior, brain regional volumes, and neurochemistry in mice. Alcohol Clin Exp Res. 2011; 35:671-688. [PubMed: 21223304]

Crews F, Nixon K, Kim D, Joseph J, Shukitt-Hale B, Qin L, Zou J. BHT blocks NF-kappaB activation and ethanol-induced brain damage. Alcohol Clin Exp Res. 2006a; 30:1938-1949. [PubMed: 17067360]

Crews FT, Braun CJ, Hoplight B, Switzer RC 3rd, Knapp DJ. Binge ethanol consumption causes differential brain damage in young adolescent rats compared with adult rats. Alcohol Clin Exp Res. 2000; 24:1712-1723. [PubMed: 11104119]

Crews FT, Mdzinarishvili A, Kim D, He J, Nixon K. Neurogenesis in adolescent brain is potently inhibited by ethanol. Neuroscience. 2006b; 137:437-445. [PubMed: 16289890]

Crews FT, Nixon K, Wilkie ME. Exercise reverses ethanol inhibition of neural stem cell proliferation. Alcohol. 2004; 33:63-71. [PubMed: 15353174] 
Crews FT, Qin L, Sheedy D, Vetreno RP, Zou J. HMGB1/ TLR receptor danger signaling increases brain neuroimmune activation in alcohol dependence. Biol Psychiatry. in press.

Crews FT, Zou J, Qin L. Induction of innate immune genes in brain create the neurobiology of addiction. Brain Behav Immun v25. 2011; (Suppl. 1):S4-S12.

Dantzer R, O'Connor JC, Freund GG, Johnson RW, Kelley KW. From inflammation to sickness and depression: when the immune system subjugates the brain. Nat Rev Neurosci. 2008; 9:46-56. [PubMed: 18073775]

Ehlers CL, Criado JR, Wills DN, Liu W, Crews FT. Periadolescent ethanol exposure reduces adult forebrain ChAT+IR neurons: correlation with behavioral pathology. Neuroscience. 2011; 199:333-345. [PubMed: 22033458]

Fages C, Nolo R, Huttunen HJ, Eskelinen E, Rauvala H. Regulation of cell migration by amphoterin. J Cell Sci. 2000; 113(Pt 4):611-620. [PubMed: 10652254]

Fang P, Schachner M, Shen YQ. HMGB1 in development and diseases of the central nervous system. Mol Neurobiol. 2012; 45:499-506. [PubMed: 22580958]

Fernandez-Lizarbe S, Pascual M, Guerri C. Critical role of TLR4 response in the activation of microglia induced by ethanol. J Immunol. 2009; 183:4733-4744. [PubMed: 19752239]

Fortier CB, Steffen EM, Lafleche G, Venne JR, Disterhoft JF, McGlinchey RE. Delay discrimination and reversal eyeblink classical conditioning in abstinent chronic alcoholics. Neuropsychology. 2008; 22:196-208. [PubMed: 18331162]

Freedman M, Oscar-Berman M. Spatial and visual learning deficits in Alzheimer's and Parkinson's disease. Brain Cogn. 1989; 11:114-126. [PubMed: 2789813]

Garg AD, Nowis D, Golab J, Vandenabeele P, Krysko DV, Agostinis P. Immunogenic cell death, DAMPs and anticancer therapeutics: an emerging amalgamation. Biochim Biophys Acta. 2010; 1805:53-71. [PubMed: 19720113]

Gruber E, DiClemente RJ, Anderson MM, Lodico M. Early drinking onset and its association with alcohol use and problem behavior in late adolescence. Prev Med. 1996; 25:293-300. [PubMed: 8781007]

Hanke ML, Kielian T. Toll-like receptors in health and disease in the brain: mechanisms and therapeutic potential. Clin Sci. 2011; 121:367-387. [PubMed: 21745188]

Hanson KL, Medina KL, Padula CB, Tapert SF, Brown SA. Impact of adolescent alcohol and drug use on neuropsychological functioning in young adulthood: 10-year outcomes. J Child Adolesc Subst Abuse. 2011; 20:135-154. [PubMed: 21532924]

He J, Crews FT. Increased MCP-1 and microglia in various regions of the human alcoholic brain. Exp Neurol. 2008; 210:349-358. [PubMed: 18190912]

Johnston, L.; O’Malley, P.; Bachman, J.; Schulenberg, JE. Secondary school students. Vol. Vol. 1. Bethesda, MD: National Institute on Drug Abuse; 2008. Monitoring the future: national survey results on drug use, 1975-2008. Vol. xxxiv

Jurgens HA, Amancherla K, Johnson RW. Influenza infection induces neuroinflammation, alters hippocampal neuron morphology, and impairs cognition in adult mice. J Neurosci. 2012; 32:39583968. [PubMed: 22442063]

Knapp DJ, Crews FT. Induction of cyclooxygenase-2 in brain during acute and chronic ethanol treatment and ethanol withdrawal. Alcohol Clin Exp Res. 1999; 23:633-643. [PubMed: 10235299]

Kosaki Y, Watanabe S. Dissociable roles of the medial prefrontal cortex, the anterior cingulate cortex, and the hippocampus in behavioural flexibility revealed by serial reversal of three-choice discrimination in rats. Behav Brain Res. 2012; 227:81-90. [PubMed: 22061799]

MacFabe DF, Cain NE, Boon F, Ossenkopp KP, Cain DP. Effects of the enteric bacterial metabolic product propionic acid on object-directed behavior, social behavior, cognition, and neuroinflammation in adolescent rats: relevance to autism spectrum disorder. Behav Brain Res. 2011; 217:47-54. [PubMed: 20937326]

Nizri E, Irony-Tur-Sinai M, Faranesh N, Lavon I, Lavi E, Weinstock M, Brenner T. Suppression of neuroinflammation and immunomodulation by the acetylcholinesterase inhibitor rivastigmine. $\mathrm{J}$ Neuroimmunol. 2008; 203:12-22. [PubMed: 18692909] 
Nizri E, Irony-Tur-Sinai M, Lory O, Orr-Urtreger A, Lavi E, Brenner T. Activation of the cholinergic anti-inflammatory system by nicotine attenuates neuroinflammation via suppression of Th1 and Th17 responses. J Immunol. 2009; 183:6681-6688. [PubMed: 19846875]

O’Malley PM, Johnston LD, Bachman JG. Alcohol use among adolescents. Alcohol Health Res World. 1998; 22:85-93. [PubMed: 15706782]

Obernier JA, White AM, Swartzwelder HS, Crews FT. Cognitive deficits and CNS damage after a 4day binge ethanol exposure in rats. Pharmacol Biochem Behav. 2002; 72:521-532. [PubMed: 12175448]

Okun E, Griffioen K, Barak B, Roberts NJ, Castro K, Pita MA, Cheng A, Mughal MR, Wan R, Ashery U, Mattson MP. Toll-like receptor 3 inhibits memory retention and constrains adult hippocampal neurogenesis. Proc Natl Acad Sci USA. 2010; 107:15625-15630. [PubMed: 20713712]

Okun E, Griffioen KJ, Lathia JD, Tang SC, Mattson MP, Arumugam TV. Toll-like receptors in neurodegeneration. Brain Res Rev. 2009; 59:278-292. [PubMed: 18822314]

Oscar-Berman M, Zola-Morgan SM. Comparative neuropsychology and Korsakoff's syndrome. I. Spatial and visual reversal learning. Neuropsychologia. 1980; 18:499-512. [PubMed: 6449680]

Park JS, Svetkauskaite D, He Q, Kim JY, Strassheim D, Ishizaka A, Abraham E. Involvement of tolllike receptors 2 and 4 in cellular activation by high mobility group box 1 protein. $\mathrm{J}$ Biol Chem. 2004; 279:7370-7377. [PubMed: 14660645]

Pascual M, Blanco AM, Cauli O, Minarro J, Guerri C. Intermittent ethanol exposure induces inflammatory brain damage and causes long-term behavioural alterations in adolescent rats. Eur $\mathbf{J}$ Neurosci. 2007; 25:541-550. [PubMed: 17284196]

Paull TT, Haykinson MJ, Johnson RC. The nonspecific DNA-binding and -bending proteins HMG1 and HMG2 promote the assembly of complex nucleoprotein structures. Genes Dev. 1993; 7:15211534. [PubMed: 8339930]

Paxinos, G.; Watson, C. San. Diego, CA: Academic Press; 2004. The rat brain in stereotaxic coordinates.

Qin L, Crews FT. NADPH oxidase and reactive oxygen species contribute to alcohol-induced microglial activation and neurodegeneration. J Neuroinflamm. 2012; 9:5.

Qin L, He J, Hanes RN, Pluzarev O, Hong JS, Crews FT. Increased systemic and brain cytokine production and neuroinflammation by endotoxin following ethanol treatment. J Neuroinflamm. 2008; 5:10.

Qin L, Wu X, Block ML, Liu Y, Breese GR, Hong JS, Knapp DJ, Crews FT. Systemic LPS causes chronic neuroinflammation and progressive neurodegeneration. Glia. 2007; 55:453-462. [PubMed: 17203472]

Rauvala H, Rouhiainen A. Physiological and pathophysiological outcomes of the interactions of HMGB1 with cell surface receptors. Biochim Biophys Acta. 2010; 1799:164-170. [PubMed: 19914413]

Riazi K, Galic MA, Pittman QJ. Contributions of peripheral inflammation to seizure susceptibility: cytokines and brain excitability. Epilepsy Res. 2010; 89:34-42. [PubMed: 19804959]

Schoenbaum G, Shaham Y. The role of orbitofrontal cortex in drug addiction: a review of preclinical studies. Biol Psychiatry. 2008; 63:256-262. [PubMed: 17719014]

Sims GP, Rowe DC, Rietdijk ST, Herbst R, Coyle AJ. HMGB1 and RAGE in inflammation and cancer. Annu Rev Immunol. 2010; 28:367-388. [PubMed: 20192808]

Stalnaker TA, Takahashi Y, Roesch MR, Schoenbaum G. Neural substrates of cognitive inflexibility after chronic cocaine exposure. Neuropharmacology. 2009; 56(Suppl. 1):63-72. [PubMed: 18692512]

Tapert SF, Brown SA. Substance dependence, family history of alcohol dependence and neuropsychological functioning in adolescence. Addiction. 2000; 95:1043-1053. [PubMed: 10962769]

Thomas JO. HMG1 and 2: architectural DNA-binding proteins. Biochem Soc Trans. 2001; 29:395401. [PubMed: 11497996]

Trudler D, Farfara D, Frenkel D. Toll-like receptors expression and signaling in glia cells in neuroamyloidogenic diseases: towards future therapeutic application. Mediators Inflamm. 2010 
Vezzani A, Maroso M, Balosso S, Sanchez MA, Bartfai T. IL-1 receptor/toll-like receptor signaling in infection, inflammation, stress and neurodegeneration couples hyperexcitability and seizures. Brain Behav Immun. 2011; 25:1281-1289. [PubMed: 21473909]

Volz HC, Kaya Z, Katus HA, Andrassy M. The role of HMGB1/RAGE in inflammatory cardiomyopathy. Seminars Thromb Hemost. 2010; 36:185-194.

Wechsler H, Dowdall GW, Davenport A, Castillo S. Correlates of college student binge drinking. Am J Public Health. 1995; 85:921-926. [PubMed: 7604914]

White HR, Marmorstein NR, Crews FT, Bates ME, Mun EY, Loeber R. Associations between heavy drinking and changes in impulsive behavior among adolescent boys. Alcohol Clin Exp Res. 2011; 35:295-303. [PubMed: 21073485]

Yang QW, Xiang J, Zhou Y, Zhong Q, Li JC. Targeting HMGB1/TLR4 signaling as a novel approach to treatment of cerebral ischemia. Front Biosci. 2010; 2:1081-1091.

Yirmiya R, Goshen I. Immune modulation of learning, memory, neural plasticity and neurogenesis. Brain Behav Immun. 2011; 25:181-213. [PubMed: 20970492]

Zhao X, Kuja-Panula J, Rouhiainen A, Chen YC, Panula P, Rauvala H. High mobility group box-1 (HMGB1; amphoterin) is required for zebrafish brain development. J Biol Chem. 2011; 286:23200-23213. [PubMed: 21527633]

Zou J, Crews F. CREB and NF-kappaB transcription factors regulate sensitivity to excitotoxic and oxidative stress induced neuronal cell death. Cell Mol Neurobiol. 2006; 26:385-405. [PubMed: $16633891]$

Zou J, Crews F. Induction of innate immune gene expression cascades in brain slice cultures by ethanol: key role of NF-kappaB and proinflammatory cytokines. Alcohol Clin Exp Res. 2010; 34:777-789. [PubMed: 20201932]

Zou J, Vetreno RP, Crews FT. ATP-P2X(7) receptor signaling controls basal and TNFalpha-stimulated glial cell proliferation. Glia. 2012; 60:661-673. [PubMed: 22298391] 


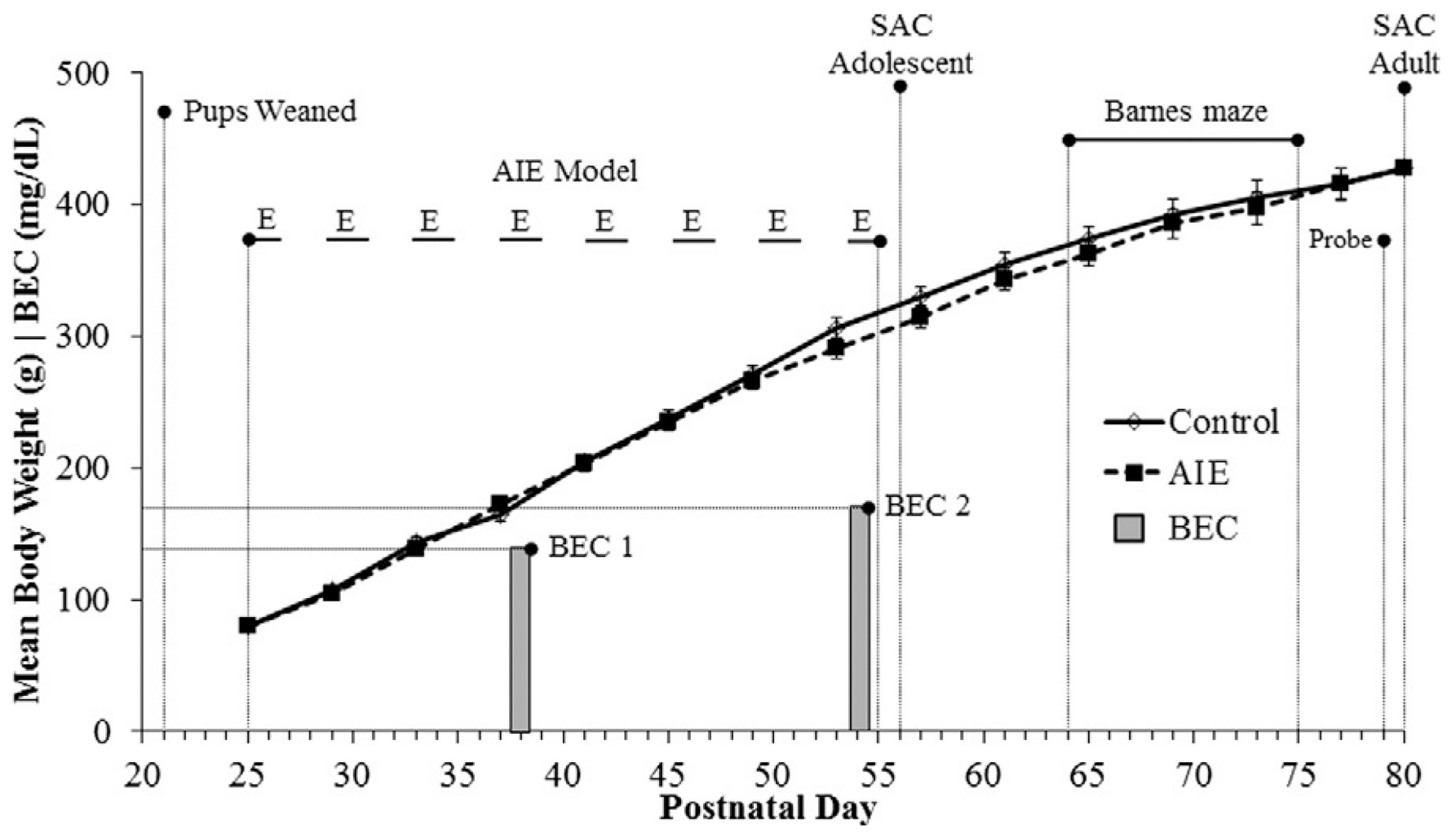

Fig. 1.

Graphical representation of the adolescent intermittent ethanol (AIE) treatment paradigm. Rats were treated from postnatal day (P) 25 to P55 with either ethanol $(5.0 \mathrm{~g} / \mathrm{kg} 20 \%$ ethanol $\mathrm{w} / \mathrm{v}$, i.g.) or a comparable volume of water on a 2-day on/2-day off administration schedule. Blood ethanol concentrations (BECs) were measured $1 \mathrm{~h}$ after ethanol treatment on P38 and P54. Spatial and reversal learning were assessed on the Barnes maze from P64 to P75, and a probe trial was administered on P79. Twenty-five days following the conclusion of AIE treatment, rats were sacrificed for immunohistochemistry and RT-PCR analysis. AIE- and control-treated rats evidenced parallel increases in body weight that did not differ as a function of ethanol treatment. 


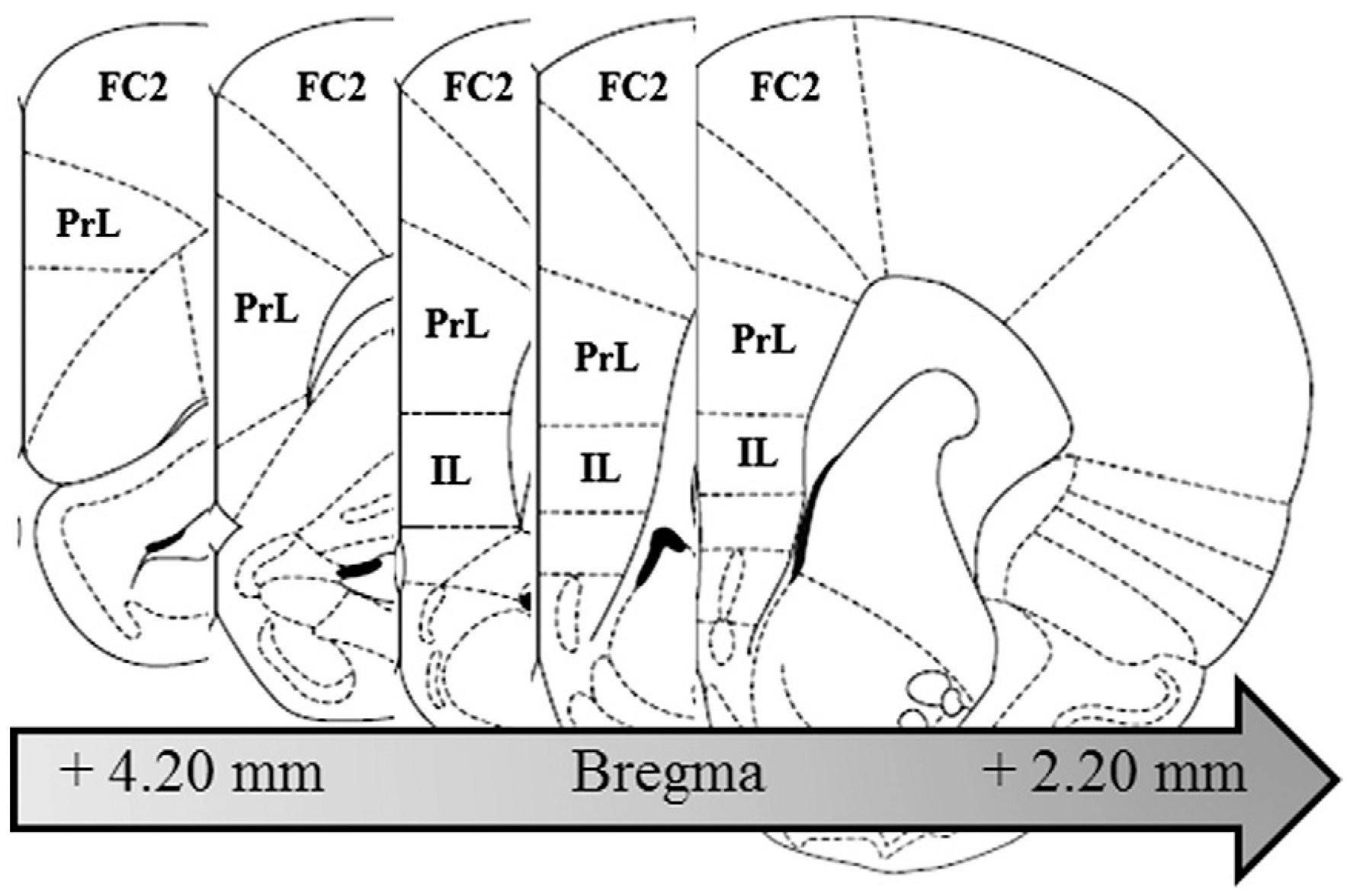

Fig. 2.

Representative micrographs of the regions of interest assessed for danger signal agonist and receptor expression in the PFC. Toll-like receptor (TLR)4, TLR2, and high-mobility group box 1 (HMGB1) + IR was measured in the prelimbic cortex (PrL, Bregma: $+4.20 \mathrm{~mm}$ to $+2.20 \mathrm{~mm}$ ) and infralimbic cortex (IL; Bregma: $+3.20 \mathrm{~mm}$ to $+2.20 \mathrm{~mm}$ ) according to the atlas of Paxinos and Watson (2004). Similarly, expression of TLR3 was measured in the frontal cortex, area 2 (FC2; Bregma: $+4.20 \mathrm{~mm}$ to $+2.20 \mathrm{~mm}$ ) according to the atlas of Paxinos and Watson (2004). 

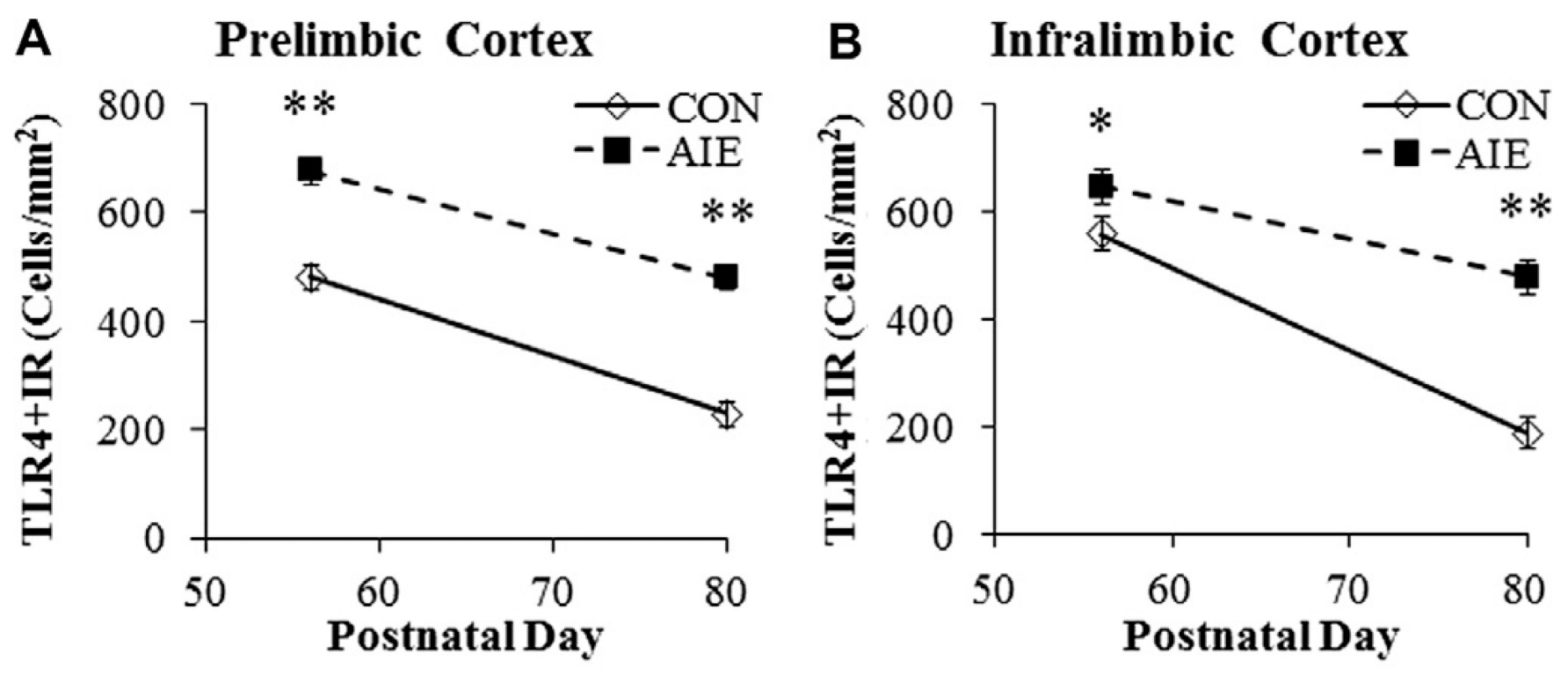

C
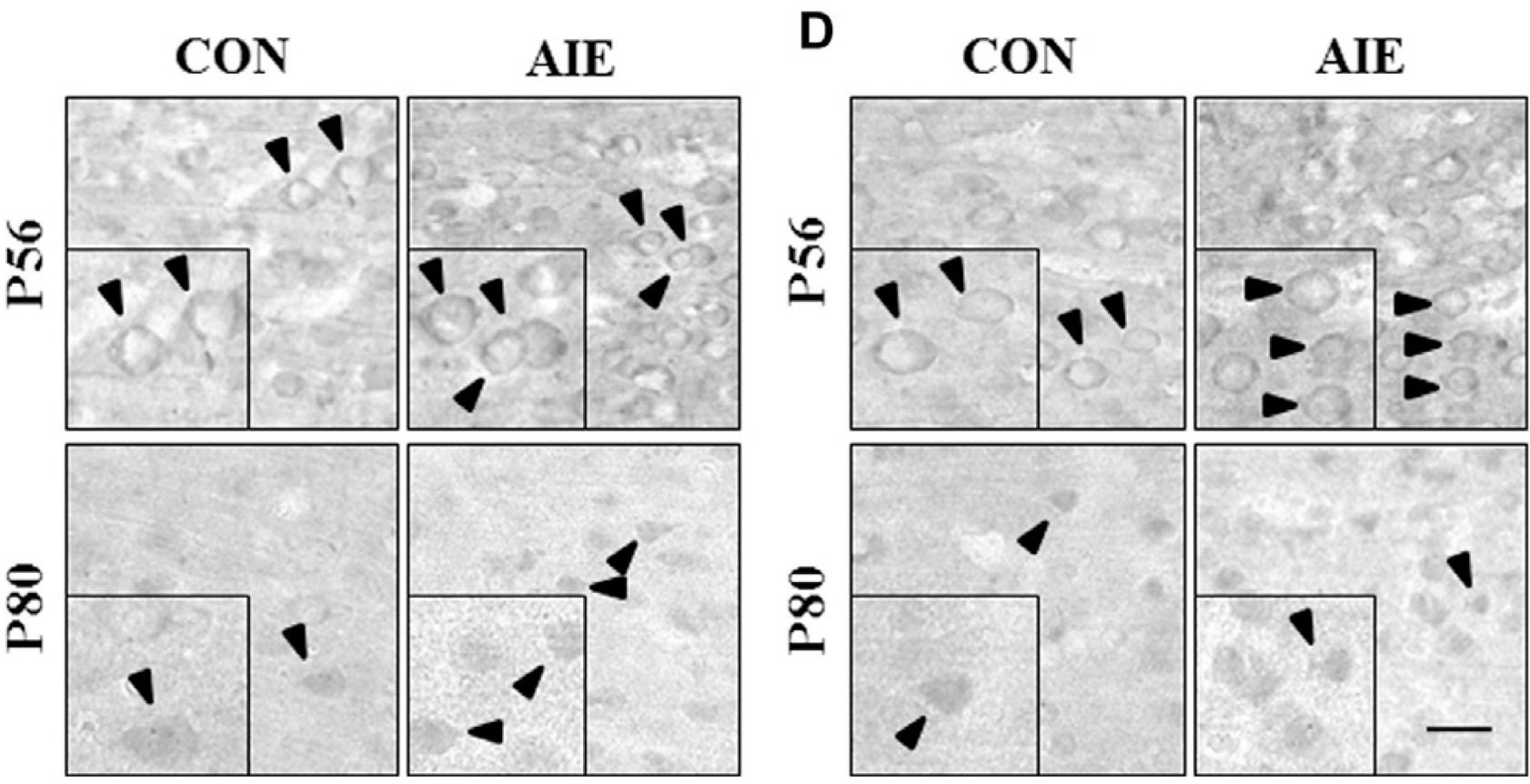

Fig. 3.

Adolescent intermittent ethanol (AIE) exposure persistently increased immunohistochemical protein expression of Toll-like receptor (TLR)4 in the adolescent (P56) and adult (P80) PFC. (A) Profile counts revealed that AIE treatment increased TLR4 + IR cells in the adolescent $(141 \pm 4 \%)$ and adult $(210 \pm 7 \%)$ prelimbic cortex, relative to CONs. (B) Assessment of profile counts in the infralimbic cortex revealed that AIE treatment increased TLR4 + IR by $116 \pm 6 \%$ in the adolescent and $254 \pm 21 \%$ in the adult, relative to CONs. Representative photomicrographs of TLR4 + IR cells in the prelimbic cortex (C) and infralimbic cortex (D) of adolescent (P56) and adult (P80) CON- and AIE-treated rats. Black arrows indicate TLR4 + IR cells. Data are presented as mean $\pm \mathrm{SEM},{ }^{*} p<0.05, * * p<0.01$, relative to CON rats. Scale bar $=20 \mu \mathrm{m}$. 


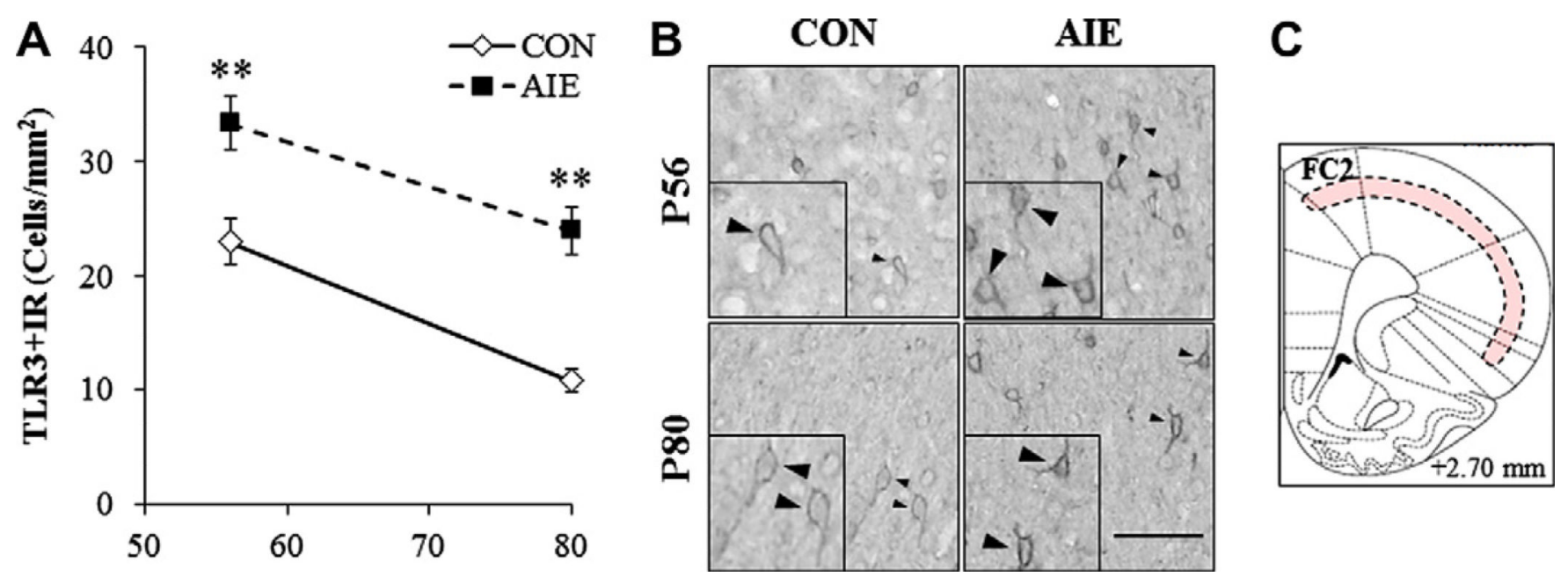

Fig. 4.

Effect of adolescent intermittent ethanol (AIE) treatment on immunohistochemical protein expression of Toll-like receptor (TLR) 3 in the adolescent and adult PFC. (A) Assessment of profile counts found that AIE treatment increased TLR3 + IR cells in frontal cortex, area 2 (FC2) of adolescent $(145 \pm 10 \%)$ and adult $(223 \pm 19 \%)$ rats, relative to CONs. Data are presented as mean $\pm \mathrm{SEM}, * * p<0.01$, relative to CON rats. (B) Representative photomicrographs of TLR3 + IR cells in the FC2 of adolescent (P56) and adult (P80) CONand AIE-treated rats. Black arrows indicate representative TLR3 + IR cells. Scale bar $=50$ $\mu \mathrm{m}$. (C) Expression of TLR3 was confined to a thin band of immunoreactivity throughout the frontal cortex. The red band reveals the area of TLR3 + IR. 

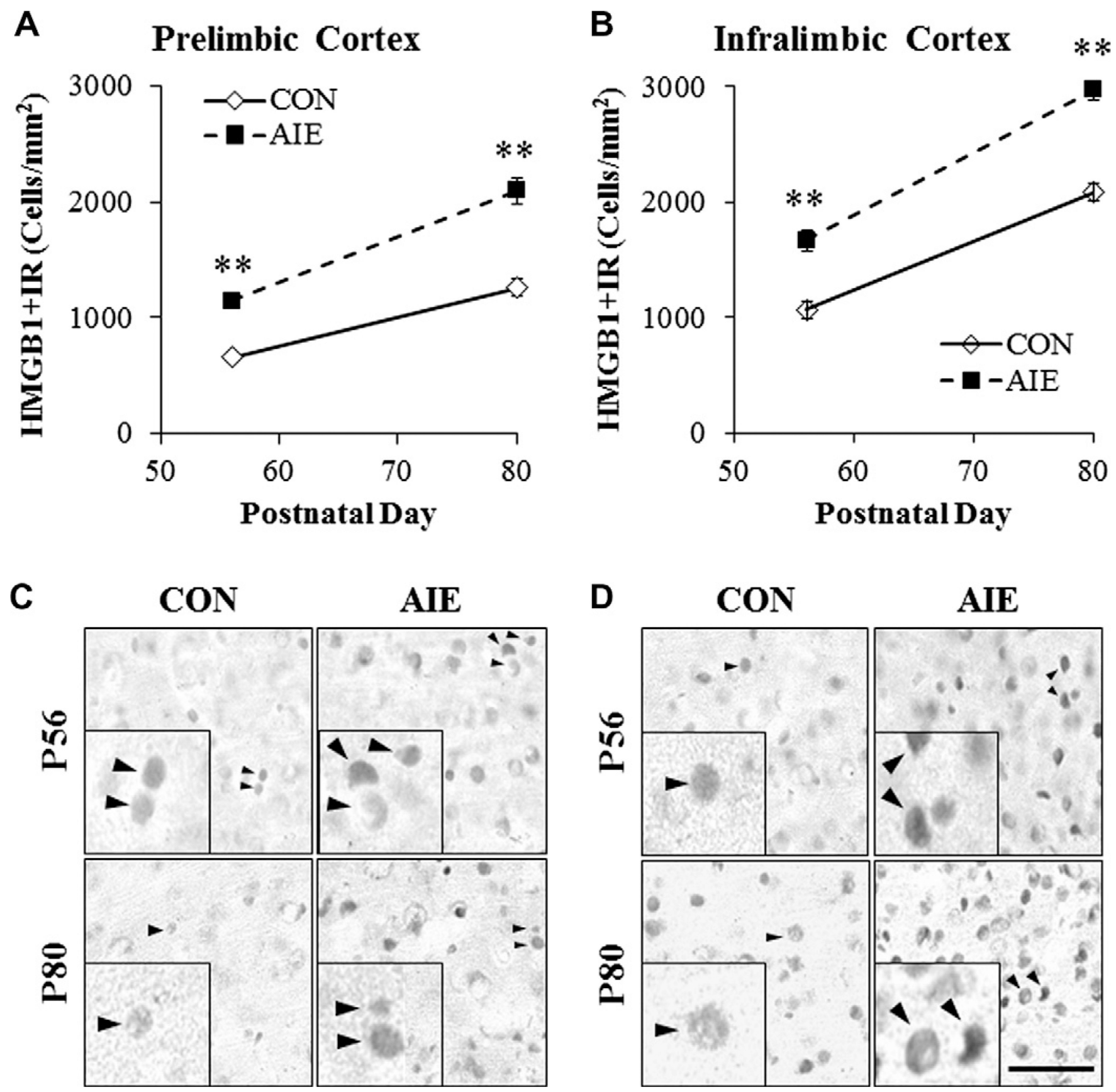

Fig. 5.

Adolescent intermittent ethanol (AIE) exposure persistently increased immunohistochemical protein expression of high-mobility group box 1 (HMGB1) in the adolescent (P56) and adult (P80) PFC. (A) Profile counts revealed that AIE treatment significantly increased the expression of HMGB1 + IR cells in the adolescent $(174 \% \pm 5 \%)$ and adult $(160 \% \pm 8 \%)$ prelimbic cortex, relative to CONs. (B) Profile counts revealed that AIE treatment significantly increased the expression of HMGB1 + IR cells in the adolescent $(157 \% \pm 9 \%)$ and adult $(143 \% \pm 4 \%)$ infralimbic cortex, relative to CONs. Representative photomicrographs of HMGB1 + IR cells in the prelimbic cortex (C) and infralimbic cortex (D) of adolescent (P56) and adult (P80) CON- and AIE-treated rats. Black arrows indicate 
HMGB $1+$ IR cells. Data are presented as mean $\pm \mathrm{SEM},{ }^{* *} p<0.01$, relative to CON rats. Scale bar $=50 \mu \mathrm{m}$. 


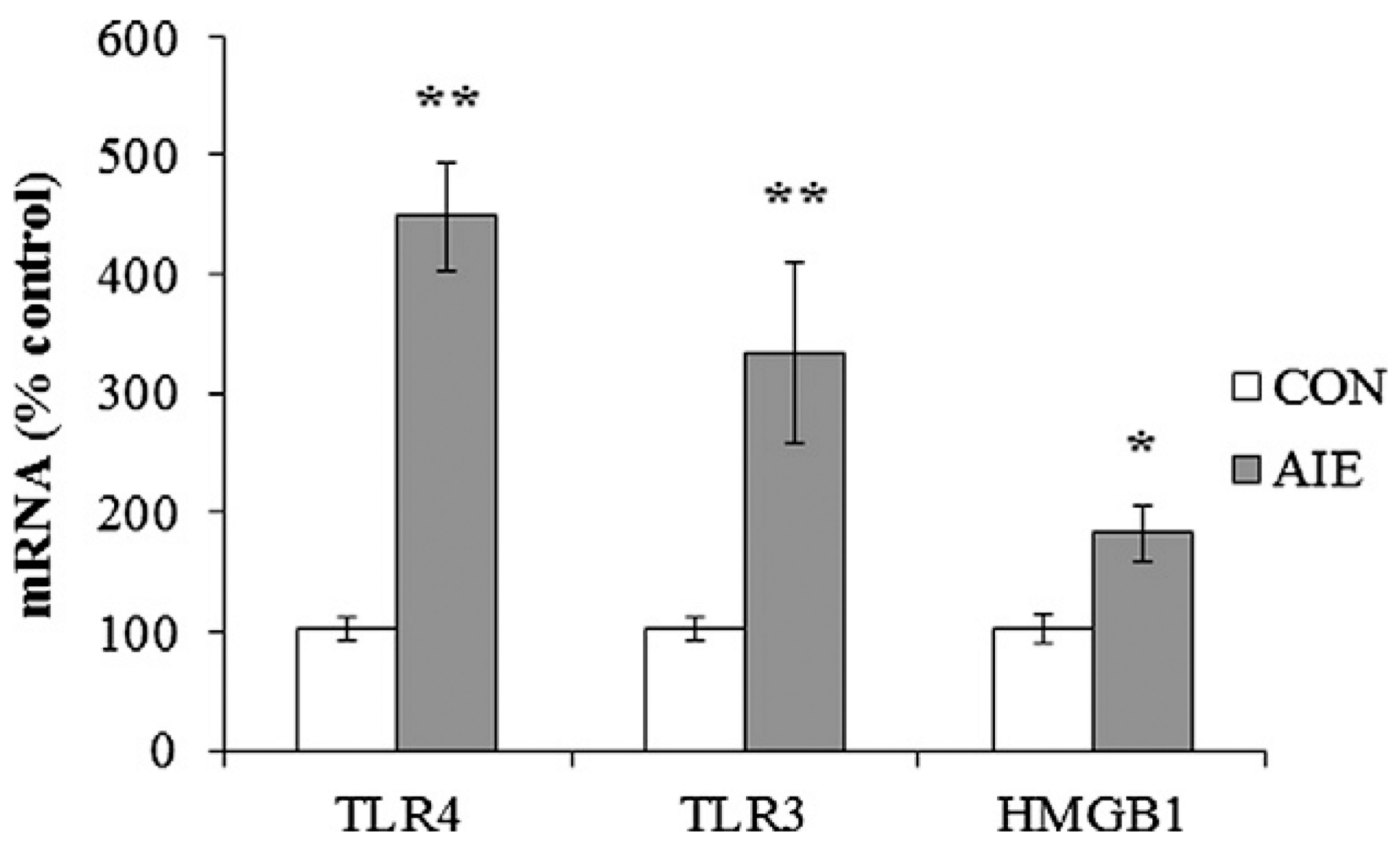

Fig. 6.

Adolescent intermittent ethanol (AIE) exposure increased mRNA levels of high-mobility group box 1 (HMGB1) and Toll-like receptors (TLRs) in the adult frontal cortex. RT-PCR assessment of innate immune danger signaling mRNA found a $>$ threefold increase of TLR4 mRNA, > twofold increase of TLR3 mRNA, and 180\% increase of HMGB1 mRNA in the frontal cortex of AIE-treated animals relative to the control (CON) subjects. Data are presented as mean $\pm \mathrm{SEM}, * p<0.05, * p<0.01$, relative to $\mathrm{CON}$ rats. 


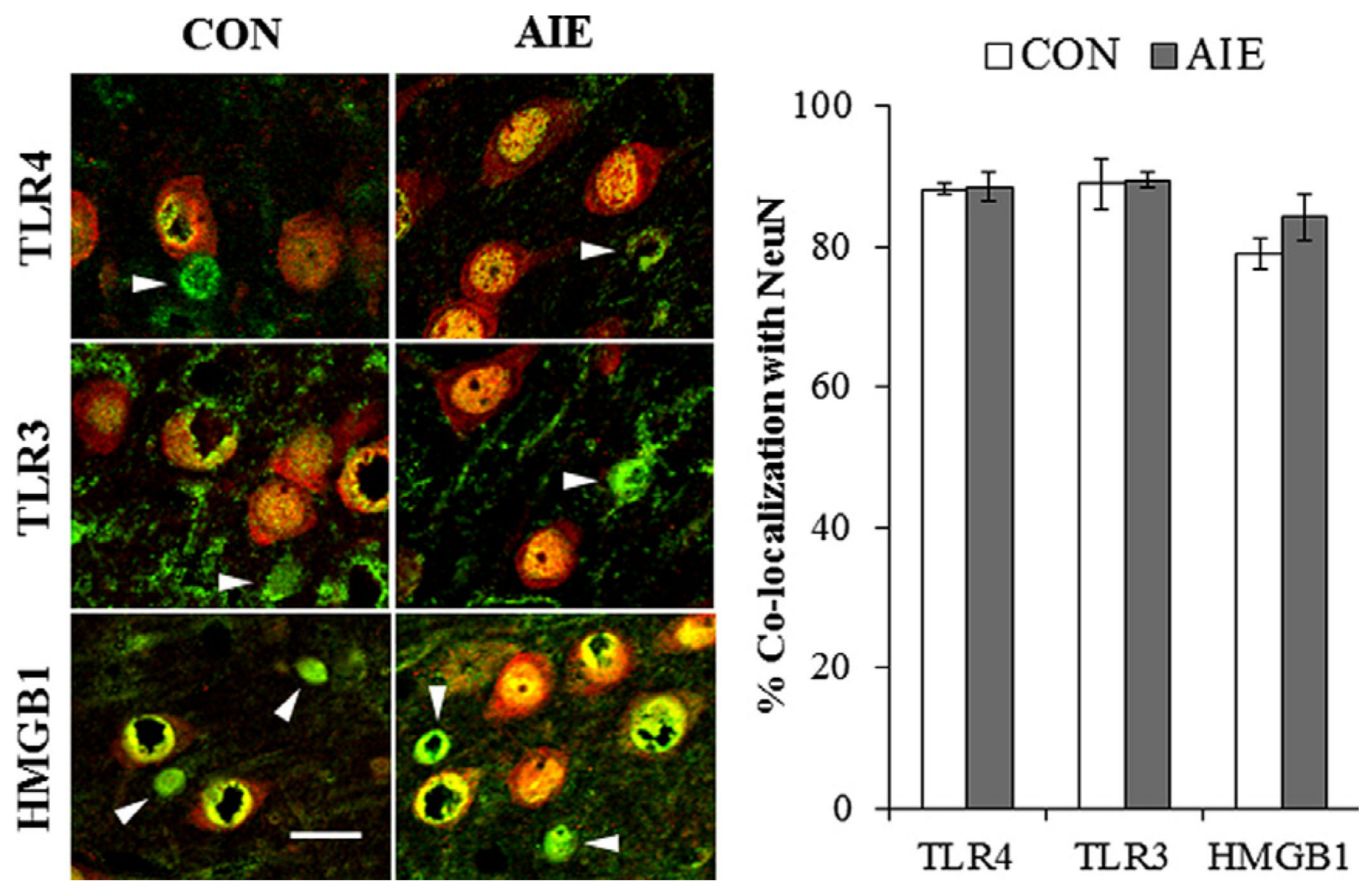

Fig. 7.

High-mobility group box 1 (HMGB1) and Toll-like receptor (TLR) immunoreactive cells are colocalized with neurons in the adult prefrontal cortex. (Left) High magnification photomicrographs of neuronal-specific nuclear protein (NeuN [red]) colocalization with TLR4, TLR3, and HMGB1 + IR cells (green) in the prefrontal cortex of adult CON- and AIE-treated rats. White arrows emphasize the HMGB1/TLR + IR cells that did not colocalize with NeuN. NeuN and HMGB1/TLR + IR cells appear yellow. Scale bar $=20 \mu \mathrm{m}$. (Right) Quantification of danger signal markers with NeuN. Data are presented as mean \pm SEM. (For interpretation of the references to color in this figure legend, the reader is referred to the web version of this article.) 

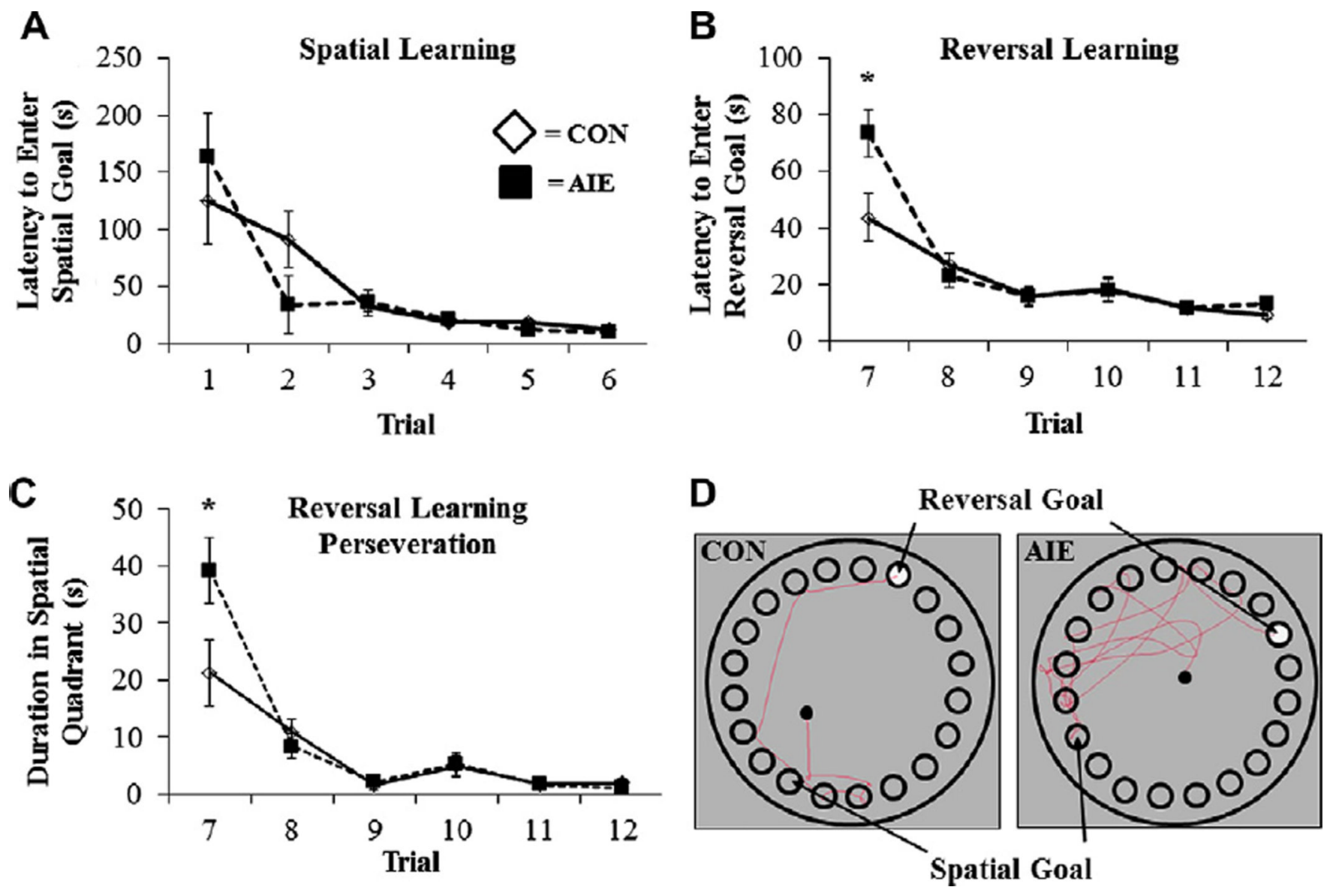

Fig. 8.

Adolescent intermittent ethanol (AIE) exposure impaired reversal learning, but not spatial learning, in adult rats on the Barnes maze. (A) AIE treatment did not affect latency to enter the spatial goal box during the spatial component of the Barnes maze relative to control (CON) subjects. (B) Following criterion learning of the spatial component, the goal box was rotated $180^{\circ}$ to assess reversal learning, or the rats' ability to 'unlearn' the spatial goal rule. AIE treatment increased the latency to locate and enter the reversal goal during the first trial (Trial 7) of reversal learning relative to CONs. Interestingly, behavioral performance of AIE-treated rats returned to CON levels by the second trial of reversal learning (Trial 8). (C) Adult rats exposed to AIE treatment evidenced increased perseveration behavior, defined as increased duration in the spatial quadrant, during the first trial of reversal learning relative to CONs. Similar to the reversal learning deficit, performance returned to CON levels by the second trial. Data are presented as mean \pm SEM, $* p<0.05$. (D) Digital representation of the pathway traversed during the first trial (Trial 7) of reversal learning from a CON- and AIEtreated animal, depicting the increased time spent by AIE rats in the spatial goal quadrant. 


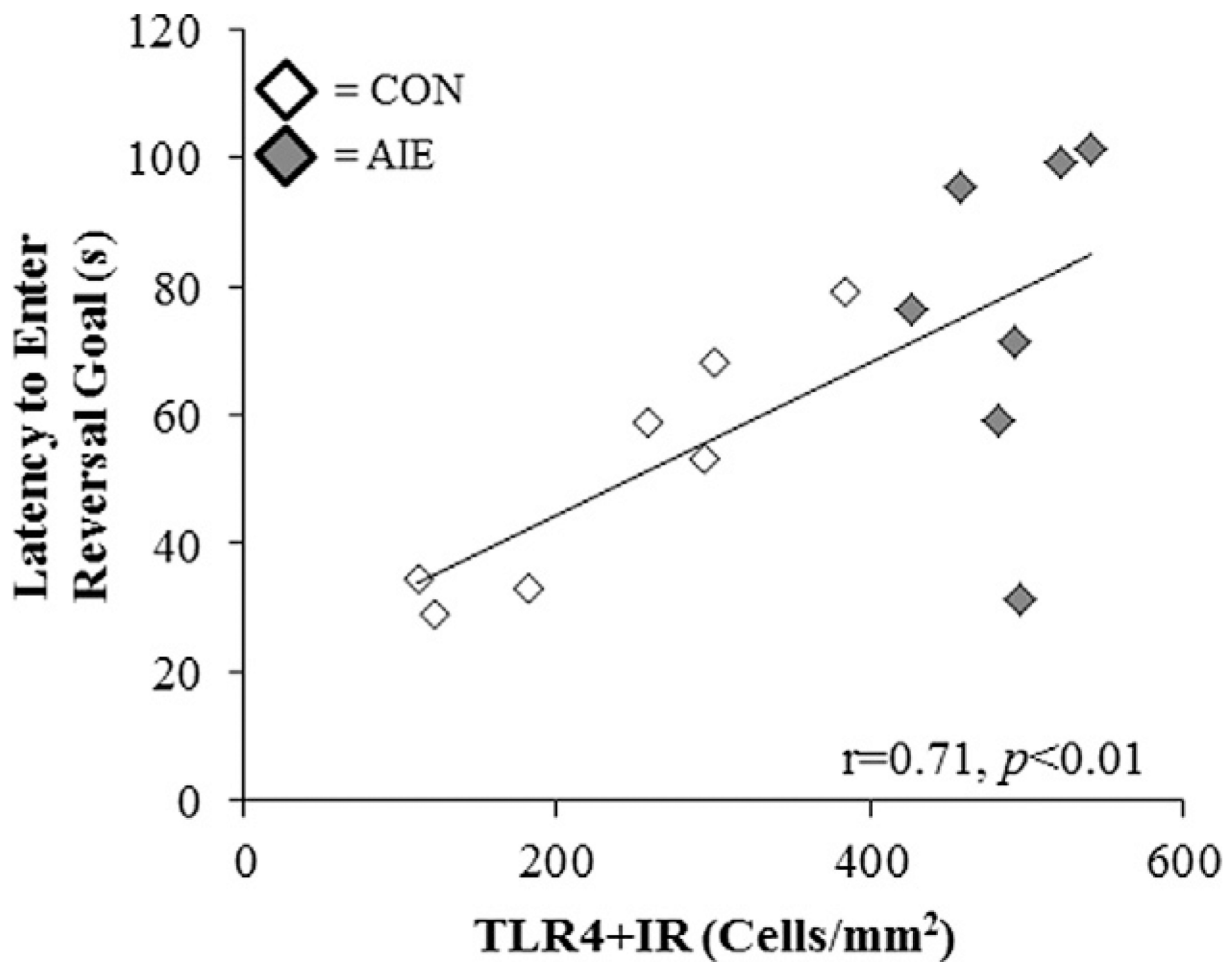

Fig. 9.

Danger signal receptor expression in the adult PFC is correlated with reversal learning performance on the Barnes maze. Performance on the Barnes maze is correlated with danger signal receptor expression in the adult PFC. Latency to enter the reversal goal box (s) during the first trial of reversal learning was positively correlated with TLR4 + IR cells in the adult prelimbic cortex. Pearson's $r$ correlation coefficient, $r=0.71, p<0.01$. 


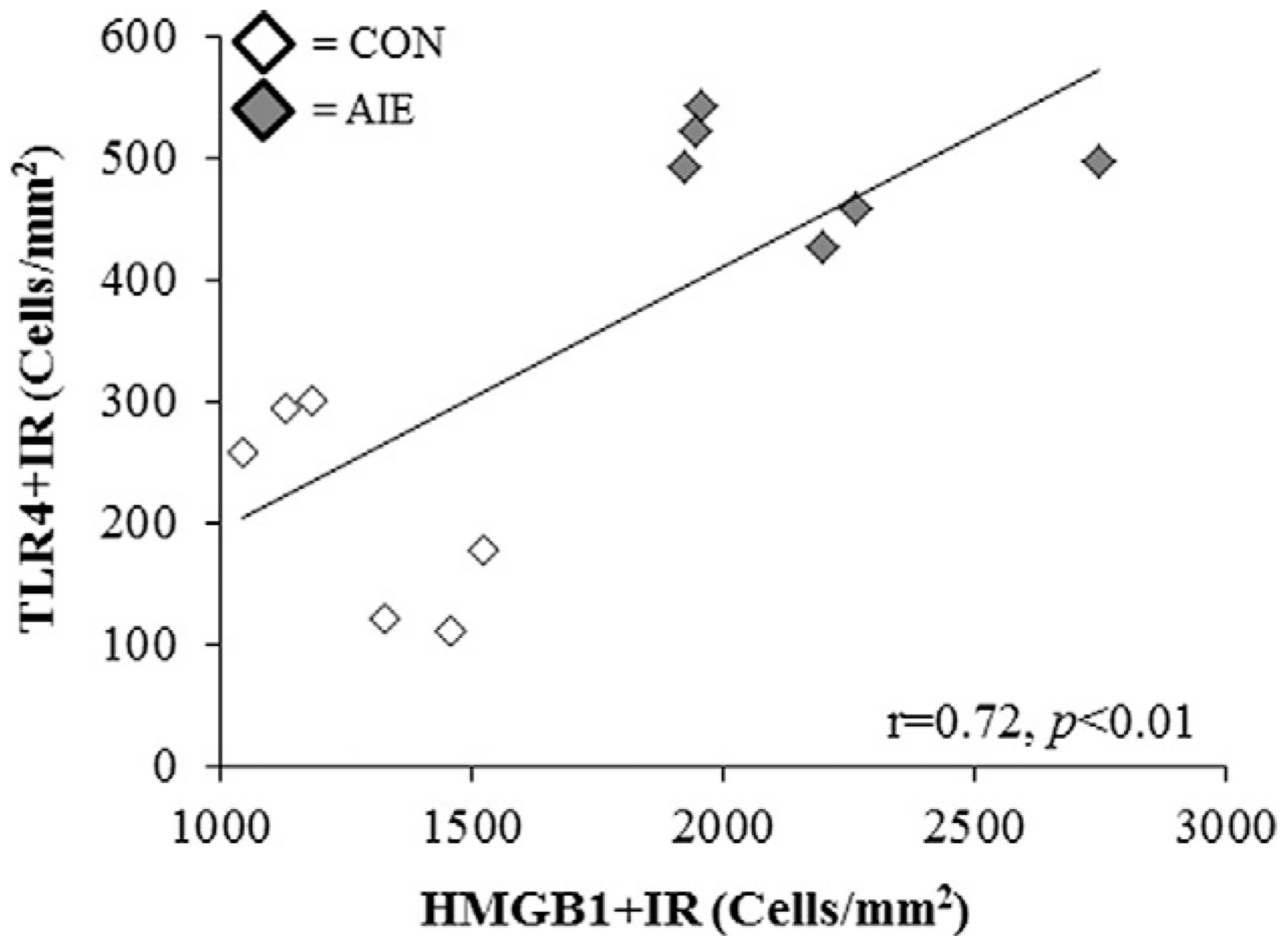

Fig. 10.

Expression of the danger signal agonist HMGB1 is correlated with the expression of danger signal receptors in the adult PFC. In the adult PFC, HMGB1 + IR in the prelimbic cortex was positively correlated with TLR4 + IR in the prelimbic cortex. Pearson's $r$ correlation coefficient, $r=0.72, p<0.01$. 


\section{A \\ Basal levels of HMGB1/TLR danger signal expression in control brain}

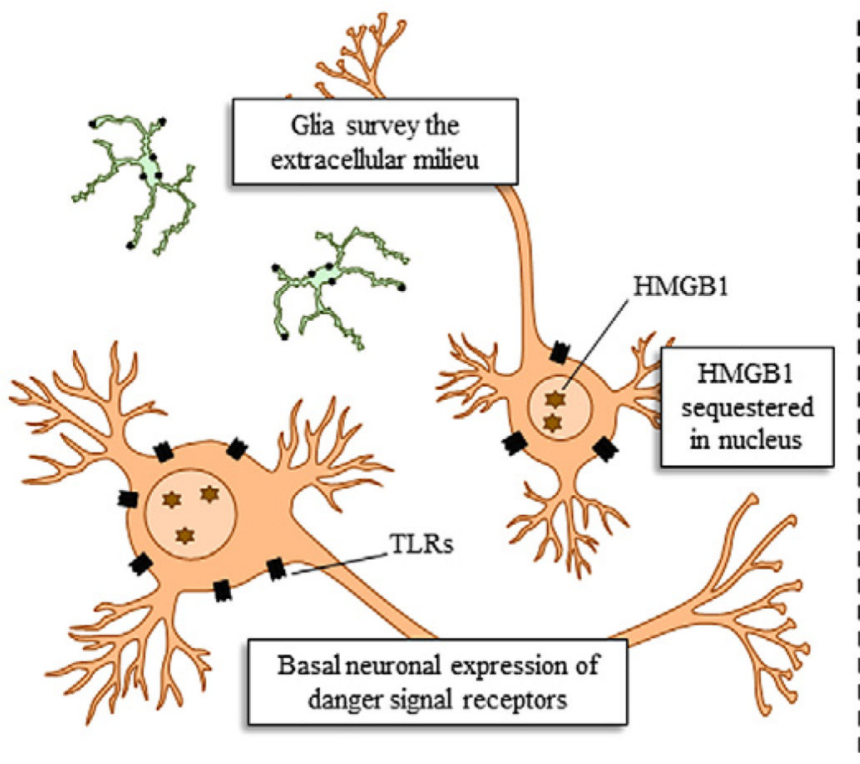

B

AIE activates the HMGB1/TLR danger signaling system that persists into adulthood

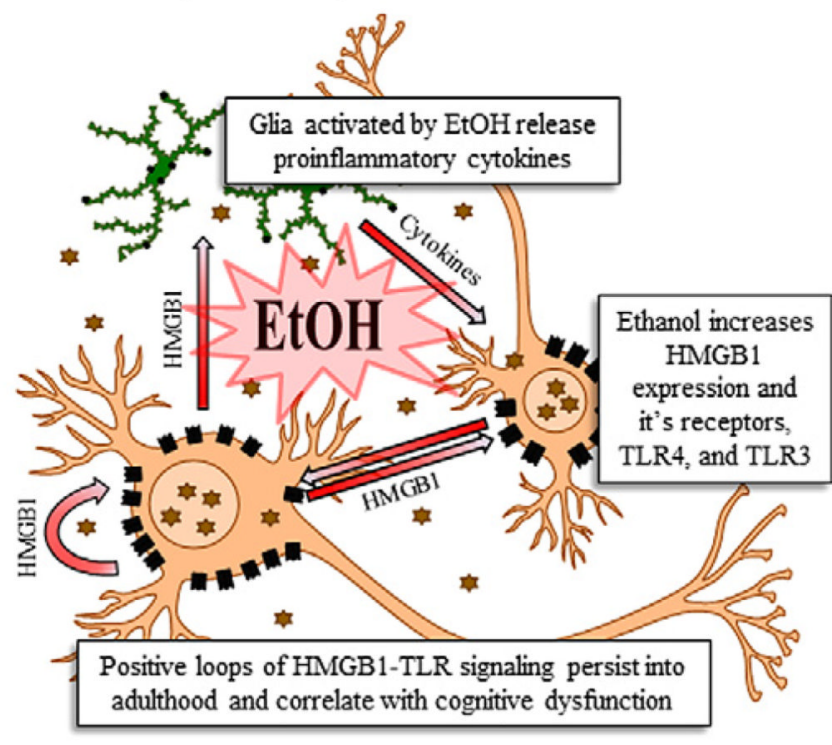

Fig. 11.

A simplified schematic of the persistent effects of adolescent binge alcohol abuse on danger signaling in the prefrontal cortex. (A) Basal expression of danger signal receptors in the control brain. In the non-pathological brain, high-mobility group box 1 (HMGB1) is sequestered within the cell nucleus where it regulates DNA bending and transcription stability (Paull et al., 1993; Thomas, 2001) as well as neuroplasticity (Fang et al., 2012). HMGB1 is ubiquitously expressed in the nucleus and is an endogenous agonist at the Tolllike receptors (TLRs). Basal physiological levels of TLRs are present on glia, which survey the extracellular environment. Neurons also express basal levels of TLRs, which play a role in neuronal plasticity and neurogenesis (Trudler et al., 2010). (B) Binge drinking during adolescence activates the innate immune danger signaling system in the prefrontal cortex that persists into adulthood. Glial cells are activated by ethanol (EtOH [Qin and Crews, 2012]) and release proinflammatory cytokines (e.g., TNFa, iNOS [Qin et al., 2008; Crews et al., 2011; Qin and Crews, 2012]). The proinflammatory cytokines result in the nuclear release of neuronal HMGB1, which becomes a proinflammatory cytokine once introduced into the extracellular environment (Garg et al., 2010; Sims et al., 2010). Through autocrine and paracrine processes, the secreted HMGB1 binds to, and increases the expression of, TLR4 and TLR3 on neurons. It also facilitates further nuclear release of HMGB1, which upon secretion, binds to TLRs on microglia, leading to further release of proinflammatory cytokines. The initial binge-drinking proinflammatory insult establishes the cyclic activation of the HMGB1/TLR danger signaling system. Once the exogenous inflammagen (i.e., alcohol) is removed, the activated glia continue to release proinflammatory cytokines in response of HMGB1 released from neurons. The glia-derived proinflammatory cytokines increase neuronal HMGB1 transcription and nuclear release, which facilitates further neuronal HMGB1 through autocrine and paracrine mechanisms. 
Table 1

List of primers for RT-PCR.

\begin{tabular}{lll}
\hline Primer & Forward & Reverse \\
\hline TLR4 & $5^{\prime}$-CCA GAG CCG TTG GTG TAT CT-3' & $5^{\prime}$-TCA AGG CTT TTC CAT CCA AC-3' \\
TLR3 & $5^{\prime}$-GCA ACA ACA ACA TAG CCA AC-3' & $5^{\prime}$-CCT TCA GGA AAT TAA CGG GAC-3' \\
TLR2 & $5^{\prime}$-GGA GAC TCT GGA AGC AGG TG-3' & $5^{\prime}$-CGC CTA AGA GCA GGA TCA AC-3' \\
HMGB1 & $5^{\prime}$-ATG GGC AAA GGA GAT CCT A-3' & $5^{\prime}$-ATT CAT CAT CAT CAT CTT CT-3' \\
$\beta$-actin & $5^{\prime}$-CTA CAA TGA GCT GCG TGT GGC-3' & $5^{\prime}$-CAG GTC CAG ACG CAG GAT GGC-3' \\
\hline
\end{tabular}


Table 2

Correlations of danger signal receptor expression in the adult prefrontal cortex with measures of reversal learning and perseveration on the Barnes maze.

\begin{tabular}{llll} 
& TLR4 & & TLR3 \\
& PrL & IL & FC2 \\
\hline Latency to reversal goal (s) & $0.71^{* *}$ & 0.43 & $0.60^{*}$ \\
Error duration (s) & $0.63^{*}$ & 0.45 & $0.68^{* *}$ \\
Error frequency & $0.54^{*}$ & 0.24 & 0.46 \\
Perseveration duration (s) & $0.56^{*}$ & 0.46 & $0.70^{* *}$ \\
Perseveration frequency & $0.59^{*}$ & 0.22 & $0.52^{*}$ \\
\hline
\end{tabular}

Pearson's $r$ correlations were conducted for the three prefrontal cortical (PFC) brain regions assessed for TLR4 + IR and TLR3 + IR cells since these regions are associated with behavioral flexibility and reversal learning. Although our correlations do not prove definitive conclusions, we found statistically significant associations for PrL-TLR4 + IR cells and FC2-TLR3 + IR cells with components of the reversal learning task. Although it is unclear as to how PFC subregions are involved in reversal learning, the correlations of reversal learning deficits with TLR4 and TLR3 expression are consistent with increased TLR3 and TLR4 expression altering prefrontal cortical function. PrL: prelimbic cortex; IL: infralimbic cortex; FC2: frontal cortex, area 2.

* Pearson's $r$ correlation coefficients were used with two-tailed significance $(p<0.05)$.

***

Pearson's $r$ correlation coefficients were used with two-tailed significance $(p<0.01)$. 
Table 3

Correlations of danger signal receptor expression with danger signal expression (HMGB1) in the adult prefrontal cortex following adolescent binge ethanol exposure.

\begin{tabular}{lllll}
\hline & & TLR4 & & TLR3 \\
\cline { 2 - 3 } & & PrL & IL & FC2 \\
\hline HMGB1 & PrL & $0.72^{* *}$ & $0.78^{* *}$ & $0.64^{*}$ \\
& IL & $0.82^{* *}$ & $0.71^{* *}$ & $0.84^{* *}$ \\
\hline
\end{tabular}

Pearson's $r$ correlations were conducted for the three prefrontal cortical (PFC) brain regions assessed for HMGB1, TLR4, and TLR3 + IR cells. Although correlations do not prove linkage, statistically significant associations were found between HMGB1, and TLR4 + IR and TLR3 + IR cells in various PFC subregions. These correlations are consistent with HMGB1-TLR signaling inducing persistent increases in brain regional HMGB1TLR expression. PrL: prelimbic cortex; IL: infralimbic cortex; FC2: frontal cortex, area 2.

* Pearson's $r$ correlation coefficients were used with two-tailed significance $(p<0.05)$.

Pearson's $r$ correlation coefficients were used with two-tailed significance $(p<0.01)$. 